\title{
EL PROGRESO DE LA EPIGRAFÍA ROMANA EN HISPANIA $(1988-1992)^{*}$
}

This chronicle contains the publications corresponding to the period pointed out systhematically ordered. I have omitted the section arranged according to discovery's places, that may be substituted by the new review Hispania Epigraphica. Special interest deserves the discovery of the Senatus consultum De Cn. Pisone Patre, unpublished for the moment. It may be also enhanced the first oath to the Emperor found in Baetica, of which I offer a text with supplements; an inscription also from the Baetica that provides information about a local magistrate's munificency, and the reconstruction of the monumental inscription from the Segovian aquaeductus, dressed by G. Alfoldy. Within the prosopographical area, it must be cited the edition of a corpus of Spanish Senators, wich includes 250 items: 180 certi and 70 incerti.

La crónica epigráfica de Hispania en este quinquenio debe abrirse de nuevo con la noticia de un hallazgo espectacular: la provincia protagonista es una vez más la Bética. Se trata del texto de un senado consulto, titulado De Cneo Pisone patre, conservado prácticamente en su totalidad en un bronce procedente de la antigua Olaura; al carácter excepcional de la conservación de un texto de esta magnitud - un total de 176 líneas - viene a unirse el hecho de que se han encontrado fragmentos de otras cinco copias, igualmente en suelo bético. La noticia de este hallazgo aún inédito ha sido presentada en el II Congreso de Historia de Andalucía (Córdoba 1991), en el Congreso celebrado en Casino en ese mismo año, y en el centro Glotz de París. Esta última conferencia, pronunciada por W. Eck, ha aparecido en los Cahiers du Centre G. Glotz ${ }^{1}$. Contiene la noticia del hallazgo múltiple, un comentario sucinto sobre la estructura y contenido del S.C. y finalmente unas reflexiones sobre el significado político de la inusual multiplicación de copias en la Bética, situación

* Esta crónica contiene las publicaciones disponibles hasta el mes de julio de 1992. Es, como de costumbre, la redacción larga de la comunicación que bajo el mismo título presenté al último Congreso Internacional (Nîmes, oct. 1992).

I W. Eck, "Das s.c. de Cn. Pisone patre und seine Publikation in der Baetica», Cahiers du Centre G. Glotz 4, 1993, pp. 189-208. 
que -según Eck - responde a una decisión personal del gobernador Vibio Sereno, cuyo nombre encabeza el texto, y no a un especial tratamiento en el conjunto del Imperio. El contenido del nuevo texto se estructura, según Eck, en las siguientes partes:

1. Praescriptum (linn. 1-4).

2. Relatio de Tiberio (4-11).

3. Acción de gracias a los dioses y a Tiberio (12-22).

4. Informe sobre la conducta de Cneo Pisón en Siria, según resulta de las sesiones del senado (23-70).

5. Proclamación del veredicto (71-123).

6. Agradecimiento del senado a la domus Augusta, al orden ecuestre, a la plebe y al ejército (124-165).

7. Indicaciones sobre la publicación de la decisión tomada (165-173).

8. Suscriptio autógrafa de Tiberio (174-176).

Está claro que podemos continuar hablando de «progreso» en la Epigrafia de Hispania, y ello no sólo por el excepcional hallazgo que acabamos de reseñar sino también por el número de inscripciones publicadas en los últimos años: en 1987, la Comisión redactora de la segunda edición del CIL Il daba como total de inscripciones hispanas la cifra de $16.500^{2}$; la comunicación presentada al Congreso de Nîmes (oct. 1992) por el responsable de la Academia de Berlín nos da la cifra de 19.000 .

Por otra parte, son ya varios los epigrafistas españoles que han querido ofrecer un balance de este progreso; un ejemplo es la panorámica que $\mathrm{M}$. Mayer presentó en el citado Congreso de Nîmes sobre los últimos veinticinco años de epigrafía hispana; otro, la documentada crónica redactada por A. M. Canto bajo el título «Un veintenio clave para la Epigrafia en España» ${ }^{3}$. Ninguno de ellos sustituye sin embargo la tarea que tomé sobre mis hombros hace ya veinte años: la de recoger las novedades de epigrafia hispana cada lustro para presentar los resultados a los Congresos Internacionales y publicar después una relación completa en la revista EMERITA ${ }^{4}$.

${ }^{2}$ Cf. la intervención de A. U. Stylow en el Coloquio sobre Epigrafia Juridica Romana, Pamplona, abril 1987 (ed. 1989), p. 30. Citaremos esta publicación en adelante como EJR.

3 Boletín de la Asociación Española de Amigos de la Arqueologia 30-31, diciembre 1991, pp. 247-270, con carácter selectivo. Otras crónicas: G. Fabre, «Chronique IV (19831987)», REA 91, 1989, pp. 202-207; un balance sobre Portugal romano en los cinco últimos años: J. d'Encarnação, Euphrosyne n.s. 21, 1993, pp. 461-465; sobre la región valenciana: J. Corell, «L'epigrafia romana al pais valenciá» (1982-1986), Fonaments 7, 1988, pp. 196218. Merece también citarse el Repertorio de bibliografia arqueológica emeritense, Mérida 1992, pp. 91-111 (nn. 305-427); Cl. Domergue, Actas I Congreso Internacional de Astorga Romana, II, 1988, pp. 7-101, ofrece una reseña crítica de los trabajos consagrados a las minas del N-O hispánico entre 1968 y 1986.

4 Vid. EMERITA 41, 1973, pp. 109-128; 47, 1979, pp. 35-86; 53, 1985, pp. 205-248; 59 , 1991, pp. 225-274. 
Se impone aquí un recuerdo a los colegas desaparecidos en estos últimos cinco años: el inolvidable Sir Ronald Syme; el que fue primer presidente de la Asociación Internacional de Epigrafia Griega y Latina (AIEGL), G. Mihailov, y el Secretario General de la Asociación, M. Le Glay. Es necesario traer también a la memoria el recuerdo de los queridos colegas españoles, S. Mariner, A. Balil y A. Blanco Freijeiro: que Dios les dé su paz.

Es hoy por fin realidad la deseada existencia de un repertorio que recogiera el material epigráfico publicado sobre España Romana: la revista Hispania Epigraphica ha reemplazado ventajosamente a su antecesora Hispania Antiqua Epigraphica cuyas noticias alcanzaron hasta 1969. Hispania Epigraphica, editada por la Universidad Complutense de Madrid, ha iniciado su carrera en 1989, y lleva publicados tres números hasta la fecha, con un total de más de 2.000 entradas; el material viene ordenado por provincias. La existencia de este instrumento de trabajo, junto con las necesarias limitaciones de espacio, han desaconsejado prescindir en esta crónica de los apartados por provincias; recojo, en cambio, todo lo susceptible de clasificación temática en apartados que suponen una cierta ampliación temática sobre los de crónicas anteriores; puede afirmarse que, de este modo, quedan fuera de nuestra consideración solamente los epígrafes conservados muy fragmentariamente, de manera que su texto resulta inaccesible, y las inscripciones funerarias que no ofrecen particularidades encasillables en los apartados temáticos establecidos, que son los siguientes 5 :

1. General: Publicaciones periódicas; crónicas y Actas de reuniones científicas; estudios referidos a Hispania o a las provincias.

2. Colecciones epigráficas.

3. Epigrafia juridica.

4. Inscripciones de época republicana.

5. Dedicatorias imperiales.

6. Senatores y equites.

7. Ejército.

8. Sacerdocios y cultos romanos.

9. Ciudades y administración local.

10. Epigrafia prerromana: cultos y onomástica indigenas.

11. Vias y miliarios.

12. Economía y comercio: marcas de ánforas; instrumenta varia.

13. Inscripciones cristianas y de época visigoda.

14. Varia.

${ }_{5}^{5}$ Por su parte, el Ficheiro Epigrafico (FE), que viene apareciendo como suplemento de la revista Conimbriga, ha alcanzado en 1992 (hasta el ${ }^{\circ}{ }^{\circ} 42$ ) un total de 189 inscripciones. La Crónica que se viene publicando en REA ha alcanzado en $1989 \mathrm{el} \mathrm{n.}{ }^{\circ} \mathrm{IV}$, correspondiente al período 1983-1987; la parte dedicada a Hispania romana ocupa las pp. 199-266; el apartado de Epigrafia, redactado por G. Fabre, las pp. 200-207. Otra fuente estimable de información la tenemos en las páginas correspondientes a Epigrafia en el Zugangsverzeichnis que publica, como suplemento de Madrider Mitteilungen, el Instituto Arqueológico Alemán de Madrid. 
1. General: Publicaciones periódicas; Actas de reuniones cientificas; Obras de homenaje; Estudios referidos a toda Hispania o a algunas de sus provincias

Continúan apareciendo nuevas publicaciones periódicas de carácter local o regional: Anales de Arqueologia Cordobesa ha visto la luz en 1990; en este mismo año se ha iniciado Antiquitas, publicada por el Museo de Priego, también en la provincia de Córdoba; en Sevilla, el Anuario Arqueológico de Andalucia, iniciado en 1985; Florentia Iliberritana en Granada, con el n..$^{\circ} 1$ en 1990. En la provincia de Valencia (Onteniente), Alba; el Instituto Menorquino de Estudios publica Meloussa desde 1990; Aquae Flaviae aparece en 1988; y en 1991, Larouco también en Galicia. Ha reaparecido El Miliario Extravagante en marzo de 1988; esta segunda época abarca del n. ${ }^{\circ} 15$ al 41 , que corresponde a noviembre de 1992.

Son numerosas las reuniones científicas que han dedicado su atención de manera directa, aunque no siempre exclusiva, a la epigrafia; dentro de estas manifestaciones, han adquirido ya cierta tradición los Coloquios sobre Lenguas y culturas prerromanas en la Península Ibérica, que comenzaron en Andalucía en 1974; el más reciente es el V, que se celebró en Colonia en 1989, cuyas Actas han aparecido en $1992^{6}$. Algunas de estas reuniones han abordado temas monográficos: las ciudades ${ }^{7}$, las vías ${ }^{8}$, religión y sociedad ${ }^{9}, \mathrm{o}$ los mosaicos ${ }^{10}$. Otras, de ámbito más general, dedican unas páginas a Hispania, como ocurre en el Congreso Internacional celebrado con motivo del centenario de L'Année Epigraphique ${ }^{11}$; otras, por último, se restringen a límites locales ${ }^{12}$. Contienen

${ }^{6}$ Actas editadas por J. Untermann-F. Villar, Salamanca 1992. Sobre las Actas del IV Coloquio, tituladas «Studia Paleohispanica», Veleia 2-3, 1985-1986 (1987), puede verse la reseña de M. Koch, Beitrdge zur Namenforschung 25, 1990-2, pp. 219-224. En noviembre de 1992 se ha celebrado en Zaragoza un Coloquio bajo el título «Roma y las primeras culturas epigráficas del Occidente mediterráneo», actas en prensa.

${ }^{7}$ Tal es el caso de la Table Ronde Les Villes de Lusitanie Romaine, organizada por la CNRS en Burdeos, actas París 1990, y de Estudios sobre Urso, ed. J. González, Sevilla 1989. El estudio de las ciudades es el tema central del XIV Congreso Internacional de Arqueología Clásica celebrado en Tarragona, septiembre 1993.

${ }^{8}$ Simposio sobre La red viaria en España romana (Tarazona 1987), actas Zaragoza 1990; Actas del Symposium Vias Romanas del Sureste de Murcia, Murcia 1988.

9 Religio deorum, Actas del Coloquio Internacional de Epigrafia «Culto y sociedad en Occidente» (Tarragona 1988), actas Sabadell 1992 (1993).

${ }^{10}$ I Mesa Redonda hispano-francesa sobre mosaicos romanos (Madrid 1985), actas 1989.

11 «Un siècle d'épigraphie classique» (París 1988), actas 1990; sobre la Península Ibérica, R. Étienne-P. Le Roux, p. 101 ss. Al Coloquio sobre Epigrafia Juridica Romana, actas Pamplona 1989, ya me referí en mi crónica anterior (vid. EMERITA 59, 1991, p. 230, n. 19).

12 I Congreso Internacional de Astorga Romana, actas León 1988; I Coloquio de Arqueologia de Viseu, actas Viseu 1989; Coloqui Internacional de Arqueologia en Puigcerdá 
también algunos estudios de epigrafia las Actas del XX Congreso Arqueológico Nacional, y las de los Congresos de Estudios Clásicos ${ }^{13}$.

Han proliferado en este quinquenio las misceláneas ofrecidas en homenaje a estudiosos del mundo antiguo, en las que aparecen - como es natural- artículos dedicados a temas epigráficos; parte de estas obras están publicadas como Anejos a distintas publicaciones periódicas ${ }^{14}$, lo que facilita su difusión.

En los meses de mayo a julio de 1990 se presentó en Madrid una Exposición de Bronces Romanos, al tiempo que se editó un Catálogo ${ }^{15}$. En diciembre de 1987 se acabó de imprimir la cuarta edición del Portugal Romano de J. Alarçao ${ }^{16}$. Otros varios estudios se ocupan de aspectos administrativos y sociales de la antigua Lusitania ${ }^{17}$.

Contamos también con una monografia dedicada a los libertos de Hispania ${ }^{18}$ y otra que se ocupa de la etapa tardo-romana de la provincia Bética ${ }^{19}$, en la línea de trabajo iniciada por Thouvenot. Algunos estudios temáticos abarcan

(1988), actas 1990; II Congreso General de Historia de Navarra (Pamplona 1990), actas 1992 (1993), anejos $P V$ n.14.

13 XX CAN (Santander 1989), actas Zaragoza 1991; II Congreso Andaluz de Estudios Clásicos (Málaga 1984), actas 1987 (1988).

${ }_{14}$ Hom. a A. García y Bellido, Anejos de Gerión I, Madrid 1988; Alimenta dedicado a M. Ponsich, Anejos Gerión 3, Madrid 1991; a M.' A. Alonso, Cuadernos de Prehistoria y Arqueología de la Universidad Autónoma de Madrid (CuPAUAM) 16-17, 1989-90 (1991); a J. M." Blázquez, Antigüedad y Cristianismo VIII, Murcia 1991 (hay en prensa otro homenaje a este estudioso, preparado por la Universidad Complutense de Madrid); a A. Blanco Freijeiro, Estudios de Geografia e Historia 3, Madrid (Univ. Complutense) 1989; a M. Vigil, Acta Salmanticensia, Estudios Históricos y Geográficos 61, Salamanca 1989; a S. Montero, Anejos Gerión 2, Madrid 1989.

Otros homenajes: Labor omnibus unus (Hom. a Walser); en la colección Latomus está en prensa un homenaje a M. Le Glay; I Encuentro de Cultura Mediterránea (Hom. al P: Tapia), Almeria 1986 (1988); Hom. Samuel de los Santos, Murcia 1988; Hom. a Moreno Díaz; Miscelánea Arqueológica J. M. Recaséns, Tarragona 1992; Excerpta Philologica, Hom. a A. Holgado, Cádiz 1991; un homenaje a Presedo se prepara en Sevilla.

is Exposición y Catálogo sobre los Bronces Romanos en España, Madrid 1990.

16 J. Alarção, Portugal Romano, 19874. Las inscripciones publicadas por el humanista portugués A. de Resende han sido recogidas por J. d'Encarnação: Da invenção de inscrições romanas pelo humanista André de Resende, Biblos 67, 1991 (hom. a Costa Ramalho). $\mathrm{H}$. Gimeno da noticia de cinco inscripciones inéditas halladas en mss. de la Biblioteca Nacional de Madrid: Veleia 6, 1989, pp. 235-241.

${ }_{17}$ Hemos mencionado ya (supra, n. 7) la reunión dedicada a las ciudades de esta provincia donde se encuentran estudios como el de Curchin (pp. 265-276) y el de AlarçãoGorges-Mantas, referidos a toda la provincia. Hay que notar además: F. H. Stanley, Jr., "Geographical Mobility in Roman Lusitania», ZPE 82,1990, pp. 249-269. Carácter regional tiene también el estudio de F. Beltrán Lloris, «La epigrafia como índice de aculturación en el valle medio del Ebro (s. Il a. C. - II d. C.)", Actas del V Coloquio... (supra n. 6).

18 J. M. Serrano Delgado, Status y promoción social de los libertos en Hispania Romana, Sevilla 1988.

19 A. Padilla, La Provincia Romana de la Bética (253-422), Écija 1989. 
todo el ámbito hispano: así ocurre con el que recoge los testimonios epigráficos sobre el empleo del mármol en Hispania ${ }^{20}$, y con una monografia dedicada a los «artesanos y técnicos» documentados en la epigrafía de la Península ${ }^{21}$.

\section{Colecciones Epigráficas}

En este quinquenio ha iniciado su andadura un Corpus de Inscripciones de Andalucia (CILA), dirigido por J. González, del que van publicados tres volúmenes: el I corresponde a la provincia de Huelva ${ }^{22}$; el II, que constará de cuatro tomos, corresponde a la de Sevilla ${ }^{23}$. El Corpus de Inscripciones de Cataluña, cuenta ya con el volumen III, correspondiente a la provincia de Gerona ${ }^{24}$. Se ha iniciado un nuevo Corpus de las Inscripciones Romanas de Galicia 24a. Siguen apareciendo corpora de menor entidad ${ }^{25}$, adiciones a los ya existentes ${ }^{26}$ y otros

20 M. Cisneros Cunchillos, Mus. Zaragoza 6, 1987, pp. 197-220.

${ }^{21}$ H. Gimeno, Artesanos y técnicos en la epigrafia de Hispania, Bellaterra 1988, con tres inéditas de Córdoba, vid. HEp 2, 1990, nn. 315-317.

${ }^{22}$ CILA 1, Sevilla 1989. Contiene un total de $84+9$ falsas; 11 de ellas son inéditas. Las novedades, así como las innovaciones de lectura se recogen en $H E p$ 3, nn. 192-234, redactado por A. M. ${ }^{a}$ Canto.

${ }^{23}$ Aparecidos hasta la fecha: II 1 y II 2, Sevilla 1991 (CILA 2 y 3): abarcan la vega del Guadalquivir, con un total de 610 epigrafes +26 falsas: son 54 inéditas, aunque muchas de ellas conservadas muy fragmentariamente; daremos noticia de las más señaladas en los apartados correspondientes de esta misma crónica.

24 G. Fabre-M. Mayer-I. Rodá, Inscriptions Romaines de Catalogne (IRC), III (Gerona), París 1991, con 194 epígrafes de los que 170 son de Ampurias. Puede verse la reseña de IRC I y II en Gnomon 60, 1988, pp. 757-759, J. d'Encarnação. En 1990 ha aparecido una reedición de J. Sacaze, Inscriptions antiques des Pyrenées, Toulouse 1990 (1. "ed. de 1982): son 468 epígrafes, todos ellos de la Galia, en una zona para la que aún no se ha elaborado un catálogo moderno satisfactorio.

24a CIRG vol. I, La Coruña, ed. G. Pereira, La Coruña 1991.

25 R. C. Knapp, Latin Inscriptions from Central Spain, 1992. A. Rodriguez Colmenero, Aquae Flauiae I. Fontes epigráficas [sic], Chaves 1987, con lecturas que deben someterse a revisión; J. N. Bonneville-S. Dardaine-P. Le Roux, Les inscriptions romaines de Baelo Claudia, Belo V; L 'épigraphie, Madrid 1988: 16 inéditas y 15 revisadas, recogidas en $H E p$ 2, 1990, nn. 227-259, redactado por A. M." Canto; F. Beltrán Lloris, «Epigrafia y romanización en la provincia de Huesca», Annales 4, 1987, p. 19 ss.; J. M. Abascal, Inscriptiones romanas de la provincia de Albacete, Albacete 1990; J. J. Castelló, Epigrafia romana de Ebusus (EREB), Ibiza 1988.

26 J. Santos-A. Hoces, «Inscripciones romanas de Segovia I: inscripciones inéditas", Veleia 6, 1989, p. $215 \mathrm{ss} .=A E, 1989$, pp. 437-447; J. Mangas et alii, «Nuevas inscripciones de la provincia de Toledo I", Hisp. Ant. 16, 1992, pp. 239-272 (conjunto de 23 epígrafes: la mayoría inéditos, otros con rectificaciones); J. d'Encarnação, «Iscriçð̋es R. do conuentus Pacensis». Aditamenta, Trab. de Arq. do Sul 1, 1986, pp. 99-109; J. Mangas-J. Vidal, «Nuevo conjunto de inscripciones romanas de la provincia de León», MHA 9, 1988, p. 213 ss.; C. González Román, "Inscripciones romanas inéditas de la provincia de Jaén III", Florentia Iliberritana 1, 1990, pp. 147-159. 
conjuntos ${ }^{27}$; cabe destacar entre ellos el titulado Bronces juridicos romanos de Andalucia ${ }^{28}$.

\section{Epigrafia Juridica}

La epigrafia de contenido jurídico sigue siendo la reina de la epigrafia hispánica. Además del senado consulto aún inédito al que aludíamos al comienzo de esta crónica, es preciso destacar los casi innumerables estudios dedicados a la lex Irnitana: baste decir que la bibliografia sobre estas tablas ocupa ocho páginas en la última monografia publicada ${ }^{29}$; puntos debatidos son principalmente la existencia de una ley general para estos municipios de derecho latino

${ }^{27}$ L. Sagredo-D. Pradales, Epigrafia y numismática romanas del Monasterio de Silos, Abadía de Silos 1992 (conjunto de 23 epigrafes con sólo 3 inéditos, pertenecientes a las provincias de León, Orense y Burgos respectivamente); I. Rodá, Catalog de l'epigrafia $i$ de l'escultura classiques del Museu episcopal de Vic, Vic 1989; A. Álvarez-C. García Hoz, Museo de Cáceres. Guia breve de la sección de Arqueologia, Cáceres 1988. Pertenecientes a diferentes zonas geográficas o comarcas: T. Mañanes, Arqueologia de la cuenca leonesa del rio Sil, Valladolid 1988; J. L. Gamallo-H. Gimeno, «Inscripciones del norte y sudoeste de la provincia de Cáceres: revisión y nuevas aportaciones», CPHA 17, 1990, pp. 277-306; A. Mourinho, Inscripciones latinas de entre Sabor y Douro, a partir de 1947, Brigantia 6, 1-3, 1986, pp. 3-36 y 7-12, 1987, pp. 101-132 = AE 1987, 565-607; J. Corell, Inscripciones romanas del pais valenciano: Saguntum 24, 1991, pp. 193-201 (7 epigrafes: conocidos salvo uno); Id., "Contribución a la epigrafia romana de Liria», Lauro 5, 1991, pp. 173-198 (10 epigrafes ya conocidos); Id., "Inscripciones romanas de la comarca de Villa del Arzobispo", Lauro 4, 1989, pp. 183-223 (32 epígrafes conocidos); J. d'Encarnação, Epigrafia romana de Moura na epoca romana, Moura 1990, pp. 41-59 (8 epigrafes); A. Brito, «Epigrafia romana no concelho de Santo Tirso", Santo Tirso Arqueologico 2, 1992, pp. 15-33 (10 epigrafes conocidos, pero algunos procedentes de publicaciones poco accesibles); J. L. Inés Vaz, Catálogo del distrito de Viseu (19 epígrafes reeditados, cf. $A E 1987,481$ y 564). V. Espinosa - L. M. Usero, «Eine Hirtenkultur im Umbruch. Untersuchungen zu einer Gruppe von Inschriften aus dem Conventus Caesaraugustanus (Hisp. Citerior)», Chiron 18, 1988, pp. 477-504.

${ }^{28}$ Ed. J. González, Sevilla 1990. Otros conjuntos agrupados no por procedencia sino en razón del soporte material es el corpus de inscripciones musivas que prepara J. Gómez Pallarés; de este autor pueden verse: «Nuevas aportaciones al Corpus de inscripciones musivas", Bol. Arq. Tarr. 10-11, 1988-89, pp. 245-249, el estudio titulado "Nombres de artistas en inscripciones musivas latinas e ibéricas en Hispania», Epigraphica 53, 1991, pp. 59-96 ( 13 epígrafes en los que figuran nombres propios) y «Epigrafia romana sobre mosaico en Hispania», Religio deorum (supra nt.9), pp. 261-270. Una selección de monumentos lusitanos de carácter funerario y origen rural presenta J. d'Encarnação, "L'epigraphie du village a l'extrème occidente (sic) d'Hispania», Epigrafia e Antichitá 12, pp. 237-259. B. Rémy ha reunido las inscripciones de médicos halladas en la Península Ibérica, REA 93 $3-4,1991$, pp. 321-364; las que contienen datos sobre la educación han sido recogidas por F. H. Stanley, Ibid., pp. 299-320.

${ }^{29}$ F. Lamberti, "Tabulae Irnitanae», municipalità e "ius Romanorum», Nápoles 1993. Contiene: edición con traducción italiana, estudio del contenido, vocabulario de las leyes municipales hispánicas. Una reseña publicará en Iura A. d'Ors; otra prepara J. González para $S D H I$. 
-la que ha llamado d'Ors Lex Flauia - y el precedente de una lex municipalis que dataría de época augústea, según parece deducirse del texto mismo de la Irnitana ${ }^{30}$. Otro problema general importante es el de la interpretación del ius latii y su relación con la ciuitas Romana ${ }^{31}$. Especial atención merecen los trabajos de Simshäuser, que ha estudiado el conjunto de disposiciones que regulan el procedimiento civil en un municipio latino, e.d. el contenido de los capítulos 84 a 93 de la ley; concluye que la competencia municipal estaba concebida en su conjunto como de jurisdicción inferior; debe pensarse que se practica según las normas de procedimiento puramente romanas; la introducción de reglas jurídicas y de privilegios administrativos romanos, contribuían sin duda a reforzar la unidad del Imperio; opina Simshäuser que había en esta época en la Bética un edicto provincial que contendría un álbum de fórmulas de acción propuestas por el gobernador, enriquecidas con cláusulas procesales $y$ otras promesas de protección jurídica ${ }^{32}$. Se han estudiado además, entre

${ }^{30}$ La postura de F. Lamberti, op. cit., es negativa en ambos puntos. W. D. Lebek, ZPE 93, 1992, pp. 297-304, que propone correcciones al texto publicado en JRS 76, 1986, $<$ LXXVI> y <LXXXVI>, cree que hay un texto subyacente a todas las leyes: una ley comicial de Domiciano que sería un "formulario" en el que estarían basadas todas las leyes municipales del tipo de la Imitana. A este respecto, parece elocuente el hecho de haberse encontrado (también en territorio bético) tres fragmentos con escritura sin columnas, correspondientes a R. 67 y 68-71, en las que quedan en blanco los lugares en que deberían figurar datos numéricos concretos (v. F. Fernández, ZPE 86, 1991, pp. 125-127: todo parece indicar que se trata precisamente de un modelo adaptable a diferentes comunidades. G. Luraschi, SDHI 55, 1989, pp. 349-368 publica un importante estudio a propósito de Á. d'Ors, La ley Flavia Municipal, Roma 1986, donde establece el estado de la cuestión sobre estas dos hipótesis y expone su opinión al respecto.

${ }^{31}$ Este tema, tratado también por Luraschi, op. cit., está presente en otro grupo de trabajos: A. Chastagnol, "A propos du droit latin provincial», Iura 38, 1987, pp. 1-24; A. T. Fear, "Ciues latini, serui publici and the lex Irnitana", RIDA 37, 1990, pp. 151-166. G. Zecchini, «Plinio il vecchio e la lex Flauia Municipalis», ZPE 84, 1990, pp. 139-146; G. Mancini, "Ius latii et ius adipiscendae civitatis Romanae per magistratum nella lex Imitana», Index 18, 1990, pp. 367-388 (el examen del capitulo treinta parece contradecir la hipótesis de Braunert); F. Sturm, "Civitatem romanam consequi et la protection des droits acquis dans la lex Irnitana», Vestigia Iuris Romani, Festschrift für G. Wesener, 1992. En curso de publicación se encuentra un volumen de la serie Studia Historica de Salamanca, cuyo tema general es: "Ius Latii y derechos indigenas en Hispania».

32 W. Simshäuser, RHDFE 1989, pp. 619-650; por otra parte, este autor reseffa la ed. de J. González en JRS, la obra de A. d'Ors titulada la Ley Flavia Municipal, Roma 1986 y la edición bilingüe de A. d'Ors-J. d'Ors, Santiago de Compostela 1988 en ZSS 107, 1990, pp. 543-561: no cree que exista una ley municipal dada por Augusto; critica el sentido en que se entiende intertium, al tiempo que lamenta que J. González no haya aprovechado el comentario hecho por A. d'Ors. En el artículo titulado «Stadtrömischen Verfahrensrecht im Spiegel der lex Irnitana», ZSS 109, 1992, pp. 163-208, parece admitir la existencia de un modelo flavio de lex municipalis que está en la base de los textos coincidentes (p. 164); sin entrar en discusión, piensa que de modo similar debió de existir una lex municipalis en la que se dieran algunas normas por las que deberian regirse las comunidades resultantes del asentamiento de veteranos (pp. 173-174). 
otros aspectos, la jurisdicción de los magistrados locales y las condiciones de acceso al ordo decurionum ${ }^{33}$; se vuelven a tratar temas ya discutidos ${ }^{34}$. Otros trabajos inciden en aspectos puramente materiales ${ }^{35}$.

En un amplio artículo titulado «Nuevos fragmentos de leyes municipales y otros bronces epigráficos de la Bética» ${ }^{36}$, el director del Museo Arqueológico de Sevilla da a conocer muchos datos de interés; entre ellos destacan: a) Varios fragmentos que corresponden a una ley de la que ya anteriormente se conocían otros fragmentos que se habían atribuido a Basilippo: los nuevos bronces parecen dar con seguridad el nombre de un municipio hasta ahora desconocido, el Villonense ${ }^{37}$. b) Otros tres fragmentos contienen pasajes de la misma ley

33 A. Rodger, "The Jurisdiction of Local Magistrates: chapter 84 of the lex Irnitana", ZPE 84, 1990, pp. 147-161: el comentario de J. González contiene algunos errores que oscurecen el texto de la ley sobre este punto; critica la traducción de Crawford en algunos lugares; J. Nicols, "On the standard size of the ordo decurionum", ZSS 105, 1988, p. 714 ss.; H. Horskotte, "Dekurionat u. römisches Bürgerrecht nach der lex Imitana», ZPE, 78, 1989, pp. 169-177 = $A E$ 1989.415. Otros estudios: J. M. Ribas Alba, La lex Irnitana: estructura politica y aspectos jurisdiccionales, homenaje a F. Valls i Taberner XVIII, Barcelona 1991, pp. 5419-5455; Id., "La naturaleza jurídica del iudicium pecuniae communis cap. 69 de la lex Irnitana», RIDA 37, 1990, pp. 335-345, en la línea de la comunicación presentada por el autor en la XLIII sesión de la Sociedad de F. de Visscher, Ferrara 1989; es un estudio comparativo con Vrs. 96. J. L. Murga, "La popularidad de las acciones en las leyes municipales de la Bética», $R I D A 38,1991$, pp. 219-284, amplía a las otras leyes conocidas el estudio titulado "Las acciones populares en el municipio de Imi", BIRD 88, 1985 (1989), pp. 209-260; R. Mentxaka, «Algunas consideraciones sobre el crimen de residuis a la luz de la legislación municipal», RIDA 37, 1990, pp. 247-334; Id., "Sobre el capítulo 73 de la lex Irnitana», Labeo 38, 1992, pp. 63-76; Id., "Descripción de la organización municipal a la luz de la tabula Irnitanan, Estudios in memoriam del prof. $L$. $M$. Diaz de Salazar, I, Bilbao 1992; M. De Bernardis, "Lex Irnitana LXXXIV-LXXXVLXXXIX: nuovi spunti per una riflessione sulla sponsio nel processo romano», Testimonium amicitiae, Milán 1992, pp. 96-144; J. Le Gall, "Quelques moyens de gagner sa vie à Flauia Irnitana au temps de l'empereur Domitien", Alimenta (hom. M. Ponsich), Madrid 1991, pp. 315-321; R. Domingo, "lus ratumque et ius potestasque», RIDA 37, 1990, pp. 135-147: precisiones en torno a la polémica sobre el concepto de ius; F. Rosa, "La lex Irnitana e la nomina del iudice», Iura 40, 1989, pp. 63-74; R. Cardilli, «Designazione e scelta del iudex unus alla luce della lex Irnitana», Rendic. Acad. dei Lincei, ser. IX, vol. III, fasc. I, Roma 1992, pp. 37-73.

34 A. Rodger, "The Lex Irnitana and Procedure in the civil courts", JRS 81, 1991, pp. 74-90: sobre el sentido del cap. 90; vuelve de nuevo sobre intertium (vid. sobre este tema mi crónica anterior, EMERITA 59, 1991, p. 235 nt. 40); F. de Martino, «Litem suam facere», $B I D R, 1988$, pp. 1-36.

35 F. Fernández-M. del Amo, La lex Irnitana y su contexto arqueológico, Sevilla 1990; J. L. Mesa, Informe técnico sobre el montaje de la lex Irnitana, RA 128, 1991, p. 9.

${ }^{36}$ F. Fernández, ZPE 86, 1991, pp. 121-136.

37 Id., ibid. J. González, Habis 23, 1992, pp. 97-119, reproduce y recompone los fragmentos (16 números) de la llamada lex Villonensis; contiene parte de los capítulos 63 a 71 de la Malacitana e Irnitana; corresponden a dos columnas de la tabla VIII de la Villonensis, que tendría 11 tablas. Hace notar que el fragmento que contiene parcialmente los cap. XXVII y XXVIII no pertenece a esta tabla. 
municipal, pero están copiados sin distribuir en columnas y tienen en blanco el lugar que ocuparían los datos numéricos; la parte conservada corresponde a los capítulos 67 y 68-71: este texto parece ser el modelo sobre el que se copiaron los ya conocidos; se hace con ello evidente la hipótesis del modelo único formulada por d'Ors ${ }^{38}$. c) Otro fragmento, de mayor tamaño, parece pertenecer a una ley colonial que no es la de Osuna ${ }^{39}$; d) un fragmento, no de ley, contiene una relación de municipios; e) otros dos más pertenecen a dos documentos diferentes, en los que se habla de portorium; en uno de ellos figura el adjetivo Conobariensis.

La Tabula Siarensis continúa siendo objeto preferido para W. A. Lebek: sus estudios sobre el tema constituyen ya casi una tradición ${ }^{40}$. Sobre la fórmula h.s.c. per relationem secundam factum est unum escribe Nicolet, que la explica en función de las prerrogativas del Emperador, que tenía derecho a enmendar los textos del Senado; entiende que el texto grabado en Siarensis es una segunda redacción, enmendada por Tiberio ${ }^{41}$. Otras observaciones han hecho: Schillinger, Fraschetti, y Galotta ${ }^{42}$.

38 Vid. supra, n. 30. Una nueva copia nos da parte de la ley municipal de Ostippo: A. Marcos Pous, Corduba Archaelogica 12, 1982-87 (publ. 1987), pp. 41-63 = HEp. 2, 1990, n. 360; contiene el capítulo 62 de Malacitana e Irnitana y la rúbrica del 63 de la Irnitana. Un pequeño fragmento, hallado en Duratón (Tarraconensis), cuya publicación prepara J. del Hoyo, parece pertenecer - según Á. d'Ors - a uno de los capitulos aún desconocidos de la ley Flavia: el correspondiente a las funciones de los Iluiri.

${ }^{39}$ Sobre la lex Vrsonensis, v. Estudios sobre Vrso (ed. J. González), Sevilla 1989; L. Fascione, "Le norme' de ambitu' nella 'lex Vrsonensis», 34, 1988, pp. 179-188.

40 W. D. Lebeck, "'Sub edicto suo proponere': Tab. Siar. frg. II col. B12 und Suet. Aug. 89.2», ZPE 77, 1989, pp. 39-41; Id., "Die mainzer Ehrungen für Germanicus, den alteren Drusus und Domitian (Tab. Siar. frg. 1 26-34; Suet. Claud. 1.3)", ZPE 78, 1989, pp. 45-82; Id., "Die postumen Ehrenbögen und der Triumph des Drusus Caesar (CIL VI $31200 \mathrm{~B}$ col. I 1-4, 9-21, 29-32; Tac. Ann. IV 9, 2)», ibid., pp. 83-91; Id., "Welttrauen am Germanicus: des neugefundene Originaldocument u. die Darstellung des Tacitus», Antike u. Abendland 36, 1990, pp. 93-102; Id., "Der Prokonsulat des Germanicus und die Auctoritas des Senats: Tab. Siar. fgr. I 22-24», ZPE 87, 1991, pp. 103-124; Id., «Ehrenbögen und Prinzentod: 9 v. Chr.-23 n. Chr.», ZPE 86, 991, pp. 47-78: aunque son desarrollos que abarcan otros monumentos, hay siempre referencias a la Siarensis. Para los estudios del mismo autor publicados hasta 1987, v. la crónica anterior, EMERITA 59, 1991, p. 237, n. 52.

${ }^{4 !} \mathrm{Cl}$. Nicolet, "La 'tabula Siarensis', la 'lex de imperio Vespasiani' et le 'ius relationis' de l'empereur au Sénat», MEFRA 100, 1988, p. 827 ss., cf. $A E 1989,408$.

${ }^{42}$ U. Schillinger-Häfele, "Die 'laudatio funebris' des Tiberius für Germanicus (zu Tabula Siarensis Fragment II col. B, 13-19)», ZPE 75, 1988, pp. 73-81; A. Fraschetti, "Osservazioni sulla Tabula Siarensis e il institium per la morte di Germanicon, MEFRA 100, 1988, pp. 807 ss.; B. Gallotta, Germanico, Roma 1987 (en apéndice III, pp. 207-210, observaciones sobre la Siarensis); otros estudios: F. Fernández, «Excesos a propósito de la Tabula Siarensis", Rev. Arq. 103, 1989, p. 29 ss.; AA. VV., La commemorazione di Germanico nelle testimonianze epigraphiche: Tabula Hebana e Tabula Siarensis, Coloquio Internacional Cassino, oct. 1991 (actas en prensa); A. M. ${ }^{a}$ Canto, La Beturia céltica: un problema de transmisión (y corolario para la Tabula Siarensis) (en prensa). 
La relativa abundancia de tesserae hospitales en suelo hispano había dado lugar a una extendida opinión que atribuía carácter celtibérico a la institución del hospitium. Contra esta opinión más o menos generalizada, se levanta ahora la voz de M. ${ }^{a}$ Dolores Dopico que sostıene que se trata de una institución indoeuropea: lo que se ha considerado característico de Hispania es común a otros pueblos ${ }^{43}$. Esta misma autora ha vuelto de nuevo su atención hacia la llamada tabula Lougeiorum fechada en el año 1 d. C. ${ }^{44}$; sobre la base de la mención conuentus Arae Augustae defiende la existencia de conuentus en el sentido pliniano del término, ya en esta época; no obstante, la autenticidad de este documento resulta sospechosa para otros autores ${ }^{45}$. Un pequeño fragmento hallado en la Bética conserva parte de un pacto de hospitalidad en el que figuraba Sex. Marius, el rico hacendado estrechamente relacionado con Tiberio ${ }^{46}$. Otra tabula que se continúa discutiendo es la de Montealegre, que contiene una renovación del pacto de hospitalidad, fechada en el año $134{ }^{47}$. Últimamente A. Montenegro propone una nueva lectura cuya principal clave es dividir el texto en dos partes: la primera de ellas tendría el verbo implícito; la segunda tendría implícito el complemento ${ }^{47 a}$; a pesar del esfuerzo realizado, la interpretación de Montenegro no termina de ser convincente: será preciso volver sobre ello en otro momento.

J. González publica de nuevo un interesante documento procedente de la Bética: el primer juramento al Emperador encontrado en esta provincia ${ }^{48}$. El texto está incompleto; lo reproduzco con los complementos que he propuesto en otro lu$\operatorname{gar}^{49}$ :

${ }^{43}$ M.a D. Dopico, «El 'Hospitium' celtibérico: un mito que se desvanece», Latomus 48 , 1989 , pp. 19-35, cf. $A E$ 1988. 670. Sobre nuevas tesserae celtibéricas: J. Velaza, «A propósito de las téseras de hospitalidad de Viana», Veleia 6, 1989, pp. 193-197.

44 Documento publicado en 1984 ( $A E$ 1984.553), v. crónica anterior, EMERITA 59, 2, 1991, p. 238 y n. 59. Ahora, M. ${ }^{a}$ D. Dopico, La Tabula Lougeiorum, Vitoria 1988.

${ }^{45}$ Cf. el comentario al estudio de Dopico en $A E$ 1989. 431 y A. M." Canto, "La Tabula Lugeiorum, un documento a debate», CuPAUAM 17, 1990, pp. 267-276. Una recensión al libro de Dopico hace G. Bravo, Gerión 7, 1989, pp. 355-357. Un estudio lingúístico de la tabla presentó S. Mariner, Actas VII Congreso Español de Estudios Clásicos, Madrid 1989, pp. 497-502.

${ }_{46}$ W. Eck-F. Fernández, ZPE 85, 1991, pp. 217-222, reconstruyen el texto hasta donde es posible.

${ }_{47}$ Publicada en 1985: $A E$ 1985. 581. Cf. las primeras discusiones suscitadas por este documento en EMERITA 59, 2, 1981, p. 239, n. 62; $A E$ 1988. 764 y $H E p$ 3.412. Más recientemente, J. Velaza, rec. A. Balil-R. Martín Valls, Tesserae hospitales de Montealegre de Campos, Valladolid 1988, en Fauentia 11, 1, 1989.

47a A. Montenegro.

48 J. González, $Z P E 72,1988$, pp. 113-127 = $A E$ 1988. 723.

49 C. Castillo, "El nuevo juramento a Augusto encontrado en la Bética», Homm. M. Le Glay, col. Latomus (en prensa). Por su parte, A. M." Canto, HEp 2. 623, seffala que debe proceder de Córdoba: esto explicaría a su modo de ver la presencia del procónsul y del cuestor; la presencia de la fórmula senatus et populus parece sin embargo hablar en contra de esta atribución. 
1 P. Petronio P. f. T[urpiliano procos.]

M. Alfio G. f. Lachete [quaestore prou. Baeticae]

T. Quinctius T. f. Silo P [ca. 20 letras mag.]

Senatus et populus c (iuitatis? ca. 15 letras]

5

in ea ue[rba iurauerunt]

[E]x mei animi sententia ut eg[o pro salute]

honore uictoria imp. Caesa[ris diui fili]

Augusti pontuficis maxu[mi et pro C. Caesaris]

10

Augusti $f$. princi(p)is iuuentutis $c$ [os.designati]

10 pontuficis et pro L. Caesaris Aug[usti f. et pro. M.]

Agrippae Augusti nepotis sente[ntia mea bellum]

faciam arma capiam eosdem [que amicos meos]

sociosque quos eis esse intel[lexero cognouero]

15

habebo eosdemque inimicos $\mathrm{m}$ [ihi infensosque]

statuam quos eorum partibus [esse animad-]

uertero et si quis aduersus [eos male dixerint]

fecerint senserint eos terr[a marique bello]

ad internicionem persequa[ $\mathrm{r}$ -

Hay una serie de estudios relacionados con temas de carácter jurídico ${ }^{50}$. Lo referente a la deditio de Alcántara lo trataremos en el apartado correspondiente a inscripciones de época republicana. Puede cerrarse este apartado con la noticia de dos documentos aún inéditos: un bronce hallado en la provincia de Zamora, que contiene al parecer una litigatio ${ }^{51}$ y el llamado "gran bronce» de Botorrita, aparecido a finales de 1992, en escritura ibérica y lengua celtibérica ${ }^{52}$.

\section{Inscripciones de época republicana}

La Tabula de Alcántara ha merecido la atención de D. Nörr, que le ha dedicado una monografía ${ }^{53}$; el mismo autor vuelve sobre el tema en un estudio

50 P. Sáez Fernández, «Estudio sobre una inscripción catastral colindante con Lacimurgan, Habis 21, 1990, pp. 205-207; J. V. Rodríguez Adrados, Auguralia, 1984, pp. 291-196: nueva interpretación de $C I L$ II 6328b, cf. $H E p$ 3. 335 (A. M." Canto); P. Guichard, "Politique flavienne et fiscalité en Hispania», $M C V$ 26, 1990, pp. 45-74: contiene las inscripciones testamentarias en las que se menciona la vicesima hereditatum; J. Muñoz Coello, "Officium dispensatoris», Gerión 7, 1989, pp. 107-119. S. Crespo Ortiz de Zárate, Hisp. Ant. 16, 1992, pp. 223-237: «La otra forma de dependencia personal: el caso de los Trophimi hispanorromanos»; Id., "La subdependencia personal en Hispania Romana; 'seruus uicarius' y las relaciones de dependencia entre siervos y libertos", Hisp. Ant. 15, 1991, pp. 239-261; Id., "Doble cognomen en -anus (-ianus) forma de atribución en el régimen esclavista», Hom. Presedo, Sevilla (en prensa); J. M. Serrano, Status y promoción social de los libertos en Hispania romana, Sevilla 1988, cf. $A E$ 1988. 672.

51 Noticia con foto, sin texto, dada por R. García Ramos, Anuario del Inst. de Est. Zamoranos, 1987, pp. 67-68; el texto lo publicará Abásolo, cf. HEp. 2, 1990. 733.

$52 \mathrm{Vid}$. las declaraciones de J. Untermann y J. de Hoz en el periódico «El Heraldo de Aragón», 8-XI-92, p. 53. Según reseña Berenguer, EMERITA 59, 1, 1992, p. 166, J. Eske sostiene que el antiguo bronce ibérico de Botorrita contiene una lex municipalis (!).

53 D. Nörr, Aspekte des römischen Völkerrechts. Die Bronzetafel von Alcantara, Munich 1989. V. la recensión de Á. d'Ors, Iura 40, 1989 (publ. 1992), pp. 139-149, con nuevas 
dedicado a la fides ${ }^{54}$; otros estudiosos han abordado aspectos parecidos del contenido de este importante bronce ${ }^{55}$.

Un balance historiográfico del bronce de Lascuta presenta M. J. Hidalgo de la Vega ${ }^{56}$.

En Taracena (provincia de Guadalajara) se ha encontrado un glans de plomo con la inscripción $Q$. Sert. / (p)ro cos. y en el reverso: $S C R .{ }^{57}$ No parece que deban basarse en este hallazgo hipótesis sobre los desplazamientos de las tropas de Sertorio. Otro plomo, éste de Carthago Noua, encontrado en Menorca, deja constancia de la familia de los Planii en aquella ciudad a finales de la República ${ }^{58}$. Una placa de Carthago Noua da el nombre de un nuevo gobernador de la Citerior entre los años 67/49 a. C.: (C?) iterius C. f. Hispa(-)/leg.pro. pr. ${ }^{59}$.

\section{Imperatores}

J. d'Encarnação ha reconstruido un epígrafe que conmemora la donación por parte de Augusto de (muros) turres e(t portas) a la ciudad de Pax Iulia en el a. 2 a. C. ${ }^{60}$. Un nuevo fragmento de Belo permite leer una dedicatoria a Británico, hijo de Claudio: piensan los editores que se puso con motivo de la elevación de la ciudad a la categoría de municipio ${ }^{61}$. La restitución de un epígrafe de Almonte (provincia de Huelva) permite ver en esta pieza una dedicatoria pro salute de Iulia Agrippina, fechada en el año $56^{62}$.

propuestas para los suplementos de la parte derecha que deben tener una longitud aproximada de 15/17 letras. En $H E p$ 3. 113 se recogen las lecturas de Nörr y las de Mariné y García Moreno en EJR. En HEp 1. 151 se da la lectura de Richardson, Hispaniae, Cambridge 1986, pp. 199-201: cf. HEp 2. 191.

${ }_{54}$ D. Nörr, Die Fides im römischen Völkerrecht, Heidelberg 1991: completa y precisa las observaciones ya hechas, en algunos puntos.

55 Ch. Ebel, «Dum populus senatusque Romanus vellet», Historia 40, 1991, pp. 439-448; B. D. Hoyos, Populus Seanoc [...] 104 B.C., 83, 1990, pp. 89-94 (conoce sólo la publicación de Gerión 2, 1984, el artículo de Richardson y la recensión de Nörr, sobre el texto de Gerión, ZSS 103, 1986, p. 633 ss); Hoyos cree que los Seanoci eran los habitantes de Seano, en el conv. Hispalense, a $120 \mathrm{kms}$. de distancia (!), cf. Id., ZPE 78, 1989, pp. 40-44.

56 St. Hist. Ant. 7, 1989, pp. 59-65.

57 J. Abascal, AEArq. 63, 1990, p. 274.

58 J. C. de Nicolás, Meloussa 2, 1991, pp. 31-48.

59 M. Koch, Chiron 19, 1989, pp. 27-35=HEp. 3. 250.

60 FE 29, 1988, n. 131, conocida de antiguo pero no registrada en CIL II, ni incluida en el Corpus del Conv. Pacensis editado por el propio D'Encarnação. En HEp. 3.207, A. M." Canto defiende la antigüedad de un epigrafe de Cala (Huelva) dedicado a Augusto por la ciudad de Segid[a], o Se [...]ntia Restituta Iue, recogida en el n. $7^{*}$ entre las falsas por J. González, CILA I, 1989, pp. 159-161, que sigue la opinión de Hübner.

${ }^{61}$ Belo V n.5 = IRPCádiz $69 \mathrm{~b}$, cf. HEp. 2. 230. Otro fragmento de Belo, el n. 6, se restituye como parte de una dedicatoria imperial, que parece referirse a Nerón o a Trajano.

62 J. González, CILA I, 1989, n. 77, cf. A. M." Canto, $H E p$ 3. 195. Reconstruyen el nombre del cónsul: P. Corn[elio Scipione cos.], y sobre este nombre, el de su colega $Q$. 
Hauschild reconstruye parcialmente la inscripción monumental del teatro de Lisboa: Ne(roni Cl)audio, diui Claudi f., Germa/nico--po(ntifici de)signato / (orc)hestram- ${ }^{63}$. Una nueva dedicatoria a Vespasiano se ha encontrado en Alcolea del Río (prov. Sevilla) ${ }^{64}$; está fechada en el a. 75 , lo que hace pensar que se puso cuando la ciudad recibiera el estatuto de municipio flavio.

Una placa de mármol, con inscripción monumental incompleta, procedente de Aritium Vetus (conv. Scallabitanus) contiene la titulatura de Trajano correspondiente al a. $115^{65}$. Una inscripción revisada de Aroche nos da una nueva dedicatoria a Adriano ${ }^{66}$; de Almodóvar (prov. Córdoba) procede una dedicatoria, fechada en el s. II que Stylow atribuye a Marco Aurelio ${ }^{66 a}$; otra, procedente de La Cañada (prov. Sevilla) es el primer ejemplo de dedicatoria a Pertinax procedente de la Bética ${ }^{67}$; dos nuevas dedicatorias a Flavio Valerio Constancio, divinizado, y a Valerio Liciniano Licinio se han encontrado en Singilia Barba ${ }^{67 a}$. Entre las muchas novedades que presenta el estudio de

Volusius Saturninus; hay que tener en cuenta, sin embargo, que hay un P. Cornelius Dolabella, coss. suff. de este mismo año, cf. G. Camodeca, ZPE 63, 1986, pp. 201-205.

En HEp. 3. 197 se reseñan las revisiones de CIL II 963, Aroche, hechas por J. d'Encarnação, Conimbriga 28, 1989, pp. 157-167 y J. González, CILA I n. 2: la hipótesis de estos dos autores que la atribuyen a Agripina, esposa de Germánico, es improbable porque se habla de Iulia y no de Vipsania; se trataría por tanto, como ya dijo Mommsen, de la madre de Nerón y se fecha entre el a. 54/59 d. C.; un epigrafe de Baelo: J. N. Bonneville-S. Dardaine-P. Le Roux, Epigrafia de Baelo Claudia, p. 27 n. 5 corresponde a Británico, no a Claudio como se había pensado, cf. $A E 1988,728$.

${ }^{63}$ Th. Hauschild, $M M 31,1990$, pp. 376 ss.

64 J. González, CILA II.1, 1991, n. 243.

65 J. R. Correia da Silva-J. d'Encarnação, $F E 36$ n. 162. Las dedicatorias a Trajano publicadas en $A E$ a lo largo de sus 100 primeros años están recogidas como apéndice en J. González (ed.), Imp. Caes. Nerua Traianus Aug., Sevilla 1993.

66 J. González, CILA I n. 4. Otras lecturas revisadas son: CIL II 3625, J. Corell, EJR, 1989, pp. 269-271 = HEp 3. 382; CIL II 3239, M. Zarhnt, ZPE 79, 1989, pp. 173-176= HEp 3. 241, donde A. M." Canto rechaza la propuesta de considerar a Adriano como conditor del municipio de Ilugo. CIL II 1517 y 2198 son una sola inscripción, dedicada a Germánico procedente de Moriles y luego llevada a Córdoba, A. U. Stylow, Chiron 19, 1989, p. 404 nt. 56, cf. $H E$ p 3. 169; sobre RIT $83=A E 1989.483$, dedicada a Caracalla, y Gerión 3, 1985, p. 331, dedicada a Philippus, v. Id., ibid., pp. 387-405. Una nueva lectura de CIL II 2072 = 5505 proponen M. G. Schmidt-M. Pastor, Chiron 19, 1989, pp. 367-386 (entre otros varias relecturas de epígrafes de la prov. de Granada); EREB (supra, n. 25) n. ${ }^{\circ}$ 25 , relectura de $C I L$ II 2660, cf. HEp 2. 52. Sobre miembros de la casa imperial que fueron patronos de Ampurias, v. infra, n. 81.

66a A. U. Stylow, Ariadna 5, 1988, pp. 145-149= Hep. 2. 295.

67 J. González, Epigrafia de La Cañada, Anejos AEArq. 9, 1988, n. 3. = HEp. 2. 636. Una revisión de lectura descubre una dedicatoria a Tranquilina Augusta no posterior al a. 267 en CIL II 2072 = 5505, v. M. G. Schmidt-M. Pastor, Chiron 19, 1989, pp. 367-386, n. 2.

${ }^{67 a}$ E. Serrano-P. Rodriguez Oliva, Baetica 11, 1988, pp. 237-256, nn. 2 y 3. 
Alföldy sobre las ciudades de Castilla la Nueva, se encuentran varias dedicatorias imperiales ${ }^{68}$.

\section{Senatores $y$ equites}

A. Caballos ha elaborado un corpus prosopográfico de los senadores hispanorromanos, dividido en dos secciones: a) certi et probabiles: un total de 180; b) incerti et incerta origine: un total de 70 ; añade una lista de 14 reiecti $^{69}$. La importancia de la aportación puede calibrarse, en principio, considerando que el número total de los hasta ahora reconocidos era de $140^{70}$; entre las unovedades» ofrecidas por Caballos destacan las siguientes familias: en la Tarraconense, Alfeni y Alfii; una rama de Pompeii seguramente emparentada con Ros$c i i$, a quienes asigna origen lusitano; los Pomponii y seis Iulii de la Lusitania y varios Memmii de origen no establecido.

En las Actas del VIII Coloquio sobre Africa Romana, celebrado en Sassari en 1990, figura una lista de los senadores africanos con cargos en Hispania y de los hispanos que sirvieron en África ${ }^{71}$. Rodríguez Neila ha publicado una segunda edición, revisada y aumentada, de su monografia sobre los Balbos ${ }^{72}$.

En ánforas de reciente publicación, figura el nombre de Tutilius Pontianus como propietario de un producto llamado Veturianum ${ }^{73}$; es el personaje ya conocido como dueño de otras variedades: Portense Tutiliorum Pontiani et Luperci (CIL XV 3826, a. 161) y Attianum Pontiani (CIL XV 4174, a. 149).

${ }^{68}$ G. Alföldy, Römische Städtewesen auf der neukastillischen Hochebene, Heidelberg 1987 (de la que recogi sólo noticia de la publicación en la crónica anterior): p. 44, dedicatoria a Trajano, entre los a. $102 / 114=A E 1987,661 ;$ p. 67 , puesta por los Ercauicenses, lectura hipotética, cf. $A E 1987.662$; p. 86, a Tiberio, a. $23 / 24=A E 1987.665=H e p 2$. 390; a Tiberio, a. $17 / 18$, pp. 80 s. $=H E p$ 2. 383; a Vespasiano y Tito, p. $82=H E p$ 2. 391; al hijo de Galieno, p. $67=H E p$ 2. 367. Una dedicatoria a Valerio Constantino en Ibiza publica J. Castelló, EREB (supra nt. 25) n. 3.

${ }_{69}$ A. Caballos, Los senadores hispanorromanos I. Prosopografia, dos vols., Sevilla 1990 (en adelante, $S H$ ). Del mismo autor, "Los senadores de origen hispano durante la República romana», Estudios sobre Urso (ed. J. González), Sevilla 1989, pp. 233-279.

${ }^{70} \mathrm{Cf}$. las listas publicadas en Tituli 5, Actas del Coloquio Internacional Epigrafia e ordine senatorio (Roma 1981), Roma 1982.

71 C. Castillo, «Relaciones entre Hispania y Africa», L'Africa Romana 8, Sassari 1991, pp. 79-99. En curso de publicación: A. Caballos, «Los magistrados de orden senatorio originatorios de Hispania en las provincias norteafricanas durante el Alto Imperio Romano" (según informe del autor, redactado contemporáneamente y con independencias del mío).

72 J. F. Rodríguez Neila, Confidentes de César. Los Balbos de Cádiz, Cádiz 1992 (1973 $)$. Otro trabajo sobre familias senatoriales es: C. Castillo, «Personas y familias notables en la Bética romana», Curso De la Grecia arcaica a la Roma Imperial, El Escorial 1989, publ. Madrid 1990, pp. 135-147.

${ }_{73}$ B. Liou-J. M. Gassend, Archaeonautica 10, 1991, p. 190. 
Se trata sin duda de L. Tutilius Lupercus Pontianus, cos. del a. 135 y su familia ${ }^{74}$. J. Remesal ha interpretado un sello anfórico de la Bética, conocido también en Germania, con las siglas LFCCV y FSCAL, como perteneciente a L. Fabius Cilo, C(larissimus) V(ir). En esta misma línea se inserta el importante estudio de F. Jacques ${ }^{75}$.

Varios fragmentos, publicados por J. González, parecen referirse a miembros de la conocida familia de los Mesii Rustici ${ }^{76}$; es posible que haya que atribuir también a esta familia la inscripción que este mismo autor publica, como de origen desconocido y conservada en Sevilla ${ }^{77}$.

G. Alföldy ha vuelto sobre la carrera de Cornelius Anullinus ${ }^{78}$; la inscripción puesta $M$. Cornelio Nigrino filio debe atribuirse, como propone el propio Alföldy, al hijo del senador M. Cornelius Nigrinus Curiatius Maternus ${ }^{79}$; A. M. Canto, rechaza la hipótesis de que Domitius Tullus, fuera el testador innominado de CIL VI 10, 229, proponiendo en su lugar a L. Licinius Sura ${ }^{80}$.

Según revisión publicada por $\mathrm{J}$. N. Bonneville, hay una serie de inscripciones de Ampurias que deben interpretarse como dedicatorias a patronos: todas

${ }^{74}$ Ausente de la lista redactada por A. Caballos (sobre el personaje, v. RE VII A $\mathrm{A}_{2}$ col. 1614 , n. 2); el epitafio de un esclavo de los Tutilii Pontiani et Luperci se encuentra en Emerita (CIL II 550).

${ }_{75}$ J. Remesal, Ariadna 6, 1989, pp. 121-153. A. Caballos recoge esta sugerencia y otras varias lecturas con ella relacionadas en su Catálogo (supra, nt. 69); no obstante, algunas de estas interpretaciones quizá sean un tanto precipitadas. Más mesuradas y mejor justificadas son las hipótesis que en este mismo sentido, establece F. Jacques, «Un exemple de concentration foncière en Bétique d'après le temoignage des timbres amphoriques d'une famille clarissime», $M C V 102,2,1990$, pp. 865-899.

76 J. González, «Epigrafia de La Cañada», Estudios sobre la Tabula Siarensis = $A E$ $1988,711,719,720$; cf. A. Canto, $H E p$. 2, 634, 650; $A E$ 1988. 721, atribuida también por González a esta familia, no parece tener vinculación alguna con los Messii, cf. $H E p$. 2. 635.

77 CILA II, n. 38: funeraria de un niño, cuya descripción corresponde a un monumento muy cuidadosamente hecho. La fórmula onomástica del difunto contiene tres items; el primero de ellos, Aelius Proculus, lo aproxima a la mencionada familia.

${ }_{78}$ G. Alfoldy, Fundberichte aus Baden-Würtenberg 12, 1987, pp. 303-305: revisión de CIL II 2073 y restitución de CIL XIII 6542, 6543.

${ }^{79}$ G. Alfoldy, Hom. a Fletcher Valls I, Valencia, 1987 , pp. $341-348=$ HEp. 2. 703. El mismo autor presenta una nueva restitución de CIL II 2075, en la que se honra a $C n$. Papirius Aelianus, que fue leg. Aug. legion. XII(II) Geminae según esta nueva lectura, vid. Est. de Derecho Romano en honor de Á. d'Ors, Pamplona 1987, pp. 141-149=HEp. 3. 186. Nuevas lecturas de inscripciones dedicadas a personas de rango senatorio en G. Alfoldy, Röm. Städtewesen... (supra nt. 68), pp. 77-84, nt. $278=$ HEp. 2. 379, p. 82 nt. 265 $=H E p .2 .385 ;$ p. 85 nt. $279=H E p .386$.

80 A. M. Canto, Chiron 21, 1991, pp. 277-324. Sobre este tema, vid. la crónica anterior, EMERITA 59, 2, 1991, p. 242 y n. 74-76. Esta misma autora publica un epígrafe puesto a una esclava de Caecina Seuerus en Aranjuez; piensa que debe tratarse de L. Caecina $G$. $f$. Seuerus, documentado en Tarraco y datado por Alfoldy en época flavia o a comienzos de s. II; el personaje sería descendiente de $A$. Caecina Seuerus, cos. a. 1 a. C., v. Hom. a Gratiniano Nieto, CUPAVAM 13-14, 1986-87, pp. 163-168. 
ellas persentan a personajes de rango senatorio o a miembros de la casa imperial ${ }^{81}$.

A la ya conocida serie de tejas con el nombre de M. Petrucidius $M$. f. leg. pro. pr., se une ahora un ejemplar encontrado en La Cañada; J. González ofrece una interpretación nueva de este conjunto, que debe fecharse, según él, no en época de Pompeyo, sino de Augusto ${ }^{82}$. Otro gobernador de la Bética, también de época augustea, figura en el nuevo juramento del Emperador encontrado en la Bética ${ }^{83}$ : se llamaba $P$. Petronius $P$. f. Turpilianus, y debía de ser abuelo del homónimo cos. ord. del a. 61: un ejemplo de la continuidad de familias senatoriales durante los julio-claudios; continuidad que se rompe con el advenimiento de la dinastía flavia.

Sobre un epígrafe fragmentario hallado en Ilurco (junto a Pinos Puente, prov. de Granada), se deduce que Plautius Siluanus Aelianus ocupó durante los a. 70-73 una magistratura imperial extraordinaria que abarca toda la Península ${ }^{84}$; es muy probable que esta misión estuviera relacionada con la extensión del ius latii en la Península por obra de Vespasiano.

Beltrán Fortes ha vuelto sobre la cronología del ara cordobesa del procónsul Arriano ${ }^{85}$.

En su estudio sobre el origen geográfico de los oficiales de rango ecuestre, registra Devijver 15 de origen hispano ${ }^{86}$. En un epígrafe de Palma del Río se da a conocer como procurator Aug., T. Mercelio Persinus de quien ya sabíamos (CIL II 2226, Corduba) que había sido aedilis y Iluir ${ }^{87}$. El ya conocido

81 J. N. Bonneville, Homm. Étienne, pp. 187-192 = HEp. 2. 395-400: M. Iun[io Silano] /pro [cosuli Asiae] / cosuli patrono; [A Terentio A. f.] / [Varroni] Mu[renae] / [p]atr[ono]; [M. Messal]ae / M[essali]no / pat[rono]; [Imperatori] / [C]ae[sari] / Aug[usto] / [patrono]; [C / L. Cae]sari / [Aug]usti / [f. patrono]; [M. Aemilio] / [Lep]id[o] / [pat]rono. Es posible que forme parte de la misma serie la inscripción publicada por P. Castafier et alii, Girona 126, 1988, p. 72 = Nolla-Casas, Carta Arq. Girona 1984, p. 169: [-]o Caesari / [—]ris / ——, que quizá correspondería a Germánico.

82 J. González, Athenaeum 67, 1989, pp. 517-523 = HEp. 3. 357.

${ }^{83}$ V. supra nn. 48 y 49 . También de época augustea es Asinius Gallus que figura como patrono en la tabula Lougeiorum, v. supra, nn. 44 y 45.

${ }^{84}$ P. Rodríguez Oliva - A. U. Stylow, Chiron 19, 1989, pp. $457-466=A E$ 1989. $425=$ HEp. 3.188. Un epígrafe fragmentario procedente del foro de Pollentia conserva la titulatura de un gobernador y la de su legado, pero faltan los nombres, vid. A. Arribas - M. Tarradell, Los foros romanos de las provincias occidentales, Madrid 1987, v. HEp. 262.

85 J. Beltrán Fortes, Mainake 10, 1988, pp. 91-110; Id., Habis 23, 1992, pp. 171-196: el ara hay que datarla a comienzos del siglo III, lo que lleva a la conclusión de que el procónsul allí citado no es Arriano de Nicomedia, sino quizá L. Annius Arrianus, cos. a. 243.

${ }^{86} \mathrm{H}$. Devijver, Bull. of the Institute of Arch. 26, 1989, pp. 107-126. A ellos debe unirse un tribunus mil. de la legio VIII originario de Urso: $Q$. Rutilius $Q$. f. Flaccus Cornelianus, dado a conocer por J. González, Est. sobre Urso, Sevilla 1989.

87 A. U. Stylow, Ariadna 5, 1988, pp. 119-145 = HEp. 2.345. J. González, CILA I n. 3 $=H E p .3 .198$ propone una revisión de lectura que supone la presencia de un innominado procurator de Nerva en la provincia de Huelva. 
Postumius Acilianus había sido procurador en la Bética, según la restitución propuesta por S. Dardaine ${ }^{88}$. La carrera del liberto Saturninus, que figura en una inscripción de Lugo y a la que Le Roux dedicó un amplio artículo en 1985, ha vuelto a ser objeto de estudio ${ }^{89}$.

J. Remesal propone nueva cronología para Sex. Iulius Posessor, conocido desde antiguo como procurator ad ripam Baetis ${ }^{90}$.

La carrera de L. Titinius Glaucus Lucretianus, que fue praefectus insularum Baliarum y poco después tribuno de la legio VI uictrix, también en la Citerior, ha sido estudiada por G. Ciampoltrini ${ }^{91}$.

\section{Ejército}

Hasta 1983 no se conocía ningún diploma militar hallado en la Península; a los dos fragmentos béticos de los que di noticia en la crónica anterior ${ }^{92}$ se unen ahora uno encontrado en Turiaso en la Tarraconense ${ }^{93}$, y otro que procede de la Bética ${ }^{94}$; el beneficiario del Turiasense es un soldado de la Cohors III Neruiorum, perteneciente al ejército de Britannia, y fechable en época antoniniana; el segundo, es un soldado de la flota, reclutado en Moesia Inferior, probablemente en el s. III.

Speidel ha reconstruido un fragmento publicado en 1960 en el que descubre la presencia de un Ala I Hispanorum en Angst ${ }^{95}$. Dos estudios de conjunto

${ }^{88}$ S. Dardaine, ZPE 91, 1992, pp. 185-191; piensa que el personaje era, como ya propuse hace años, originario de Astigi.

${ }^{89}$ M. Christol - S. Demougin, MEFRA 102, 1990, pp. 159-211: los AA. proponen una datación algo más retrasada que la defendida por Le Roux; sería manumitido por Cómodo; la dedicatoria de Lugo pudo hacerse entre 203/205; la de Pérgamo, hacia el a. 214.

90 J. Remesal, Alimenta (Hom. M. Ponsich), Anejos Gerión III, Madrid, 1991, pp. 281295; P. Guichard, Sur les procurateurs du "Kalendarium Vegetianum» et quelques notables municipaux, ibid., pp. 297-308. M. A. Marcos García presenta un estudio del procurador de Asturica Augusta C. Iulius Siluanus Melario, Astorga Romana, Actas I Congreso Internacional, Astorga 1986, pp. 219-225 y 227-235.

91 Vid. Athenaeum 67, 1989, pp. 295-296 y 70, 1992, pp. 233-236; contra la opinión de Ciampoltrini, M. G. Angeli-Bertinelli, ibid. 68, 1990, pp. 541 s. Una relectura de CIL II 3111 , en la que figura un tribunus, en J. M. Abascal, AEArq. 63, 1990, p. 271, siguiendo a Alfoldy; otro cursus ecuestre en ERClunia $32=H E p .2,99$, cf. $A E 1988,776$ y HEp. 3, 105.

92 EMERITA 59, 2, 1991, pp. 245-246, nn. 98 y $99=A E$ 1984. 529. Vid. también «Relaciones entre Hispania y África en época alto imperial», L'Africa Romana VIII, Sassari 1991 , p. 79 ss.

${ }^{93}$ F. Beltrán, El Moncayo, Ejea de los Caballeros 1989, p. 130, dio la noticia del hallazgo; posteriormente en Chiron 20, 1990, pp. 265-266 da una versión más elaborada; por otra parte, A. Balil, Epigraphica 51, 1989, pp. 254-255; cf. HEp. 3. 416.

94 W. Eck-F. Fernández, ZPE 85, 1991, pp. 209-216.

95 M. A. Speidel, ZPE 91, 1992, pp. 165-175. 
sobre la legio VII presentan una puesta al día de la investigación acerca de esta unidad ${ }^{96}$. Otras noticias se refieren a soldados de distintas legiones ${ }^{97}$. Ciento dieciséis estampillas de la Cohors I Celtiberorum se han hallado en el campamento romano de Ciudadela ${ }^{98}$.

Tsirkin da la voz de alerta sobre la excesiva valoración que hoy se hace del papel de los veteranos en la romanización de Hispania ${ }^{99}$. Contamos ahora con un Corpus de beneficiarii de todo el Imperio ${ }^{99}$. P. Le Roux recoge las nove-

96 J. M. Abascal, «La legio VII Gemina: balance de la investigación y perspectivas», Astorga Romana 1.1, pp. 317-328; M. A. Rabanal, "La legio VII: mandos y soldados", St. Hist. Ant. 6, 1988, pp. 145-155. Un nuevo tribuno de esta legión da a conocer J. González (v. supra, n. 86); J. Boube, MEFRA 102, 1990, pp. 213-216, sobre la dedicatoria puesta en Sala (Marruecos) a C. Hosidius $C n$. f. Claud. Severus, también tribuno de esta unidad, seguramente en época de Trajano. Sobre milites de esta legión: G. Alföldy, ZPE 87, 1991, pp. 163-167 = HEp. 3. 369. Un soldado perteneciente a la categoría de discens armaturae (epígrafe publicado con lectura errónea por $\mathbf{R}$. Cortes - J. M. Escola, Bull. Arq. de Tarragona 8-9, 1986-1987 (1989), pp. 55-57, cf. AE 1989. 482; J. Marcillet-Jaubet, "Un soldado lusitano de la VII Gemina en Lambaesis», $A$. Port. 5, 1987, pp. 203-208; otro, también lusitano originario de Scallabis, en Tarraco, dado a conocer por M. Mayer, «Els enterraments del parc de la Ciutat i la problematica funeraria de Tarraco", Mem. exc. 1, 1987, pp. 177-179=AE 1987. $736=$ HEp. 3. 368: la inscripción puesta por otro miles de la misma centuria, da también el nombre del centurión -Antonius Marcellus - y se data entre el fin del siglo I y el primer tercio del II; otro centurión - $L$. Cornelius Clacidus - se da a conocer en la provincia de Orense: A. Rodríguez Colmenero-S. Ferrer, Aquae Flauiae 1, 1988, n. 534, cf. HEp. 3, 272; dos primipili, en inscripción inédita contenida en los mss. de la Biblioteca Nacional: M. Mayer, Fonaments 7, 1988, pp. 224-227. A la legio VII debía de pertenecer también T. Antonius Aper, originario de Nemausus enterrado en la provincia de León: M. E. Morezón - J. Domínguez, Tierras de León 70, 1988, p. $79=A E 1988$, 762; también de origen extranjero era el Pompeianus hallado en la provincia de Alicante: Rabanal - Abascal, Lucentum 5, 1986, pp. 169-174 = AE 1988, 820. Otro soldado de la legio VII parece que debe leerse en el epigrafe publicado por Mourinho, Brigantia 7,1987, n. $44=A E 1987,596$, cf. $H E p .3,465$. Ha aparecido en León la primera lápida funeraria con el símbolo del águila: J. Mangas - J. Vidal, MHA 8, 1987, pp. 196-197.

97 En $E R C l u 55=H E p$. 2. 118 se reconstruye $A E$ 1988. 787: unn miles de la legio X; a propósito de un veterano de la legio II Augusta documentado en Navarra, vid. J. J. Sayas, ETFsu. II H." Ant. I, 1988, pp. 233-246; otro de la VI Victrix, en Burgos: cf. HEp. 3. 111.

98 M. Caamaño, Gallaecia 11, 1989, pp. 209-228.

99 J. B. Tsirkin, Gerión 7, 1989, pp. 137-147. Otros estudios sobre el ejército: N. Santos Yanguas, "Soldados Bracaraugustanos en el ejército romano", Brac. Aug. 50, 1986-87, pp. 97-129. Revisiones de epígrafes conocidos: $E R C l u 56=H E p$. 2.199, nueva interpretación de $A E$ 1988. 788: $O t<h>$ onianus es un cognomen; G. Alfoldy, $Z P E$ 87, 1991, pp. 168-172, relectura de $A E$ 1983. 487; P. Le Roux, Homm. Chastagnol, París 1992, pp. $265-275$, relectura y nueva interpretación de $I L P G r$ n. $138=I R A l$ n. 28: epigrafe del siglo IV, único en su género, que documenta la carrera de un suboficial de la guardia imperial, originario del lugar del hallazgo (prov. de Almería), en el límite entre la Cartaginiense y la Bética.

99a Corpus der gr. u. lat. Beneficiarien, ed. E. Schellmayer u. a. Stuttgart 1990. Por otra parte, Gómez Pantoja, Gerión 10, 1992, pp. 159-173, corrige la lectura de CIL 2915, donde se menciona una statio de beneficiarios consulares, única conocida en Hispania. 
dades que se han producido en torno al ejército de Hispania en el decenio que va desde la publicación de su estudio sobre este tema hasta $1992{ }^{996}$.

\section{Sacerdocios y culto}

Se han publicado, como indicamos más arriba, las Actas del Coloquio Internacional Religión y Sociedad celebrado en Tarragona en octubre de $1988^{100}$; algunos trabajos se han orientado al estudio de los documentos sobre una determinada divinidad en una determinada región o en toda Hispania ${ }^{101}$; otros, al conjunto epigráfico de un santuario concreto ${ }^{102}$.

99b «L'armèe romaine dans la Péninsule Ibèrique sous l'Empire: bilan pour une décennie», $R E A, 1992$, pp. 231-257.

100 Cf. n. 9. Los estudios de carácter general, contenidos en este volumen, son los siguientes: J. Alvar, «Los cultos mistéricos en la Tarraconense», pp. 27-46; J. M. ${ }^{a}$ Blázquez, "Religión y sociedad en las inscripciones de Salamanca», pp. 73-82; J. Corell, "El culto a Liber Pater en el S. del conv. Tarraconensis", pp. 125-143 (total de 20 epígrafes, la mayoría del hallazgo reciente, con 3 inéditos); V. Gil Mantas, "Evergetismo y culto oficial», pp. 227-250; J. del Hoyo, «Relación culto-estrato social en la Hispania Romana», pp. 303-308; A. M. "Vázquez, "Algunos problemas de la epigrafia religiosa hispanorromana», pp. 461-470. Otros estudios de carácter general: N. Dupré-M.ª J. Pérez Agorreta, «Thermalisme et religion dans le Nord de l'Hispania», Caesarodunum 26, 1992, pp. 152-169; R. Étienne, "Le Culte Impèrial, vecteur de la hierarchisation urbaine», Coll. Villes de Lusitanie (supra n. 7), pp. 215-231; M. P. González Serrano, "Consideraciones sobre el culto mitraico en Hispania», Hom. Blanco (supra, n. 14), pp. 163-185; A. Lozano, "Antropónimos griegos en la epigrafia religiosa latina», Gerión 7, 1989, pp. 207-239; J. Mangas, «Nombres y cultos en Asturica Augusta antes de su cristianización", Astorga Romana 1,1, pp. 55-74; J. A. Redondo, «La religión grecorromana en el SE cacereño», Rel. Lusitania 1, pp. 15-29; J. Rodríguez Cortés, Sociedad y religión clásica en la Bética romana, Salamanca 1991; A. M. Rodríguez Navarro, "Algunas conclusiones sobre la religión en el Conv. Bracaraugustanus», Rel. Lusitania 1, pp. 113-125.

101 Sobre Marte: P. Rodríguez Oliva, «Documentos del culto en las localidades antiguas de Osqua y Cartima», Mainake 11-12, 1989-90, pp. 181-196; G. López Monteagudo, "Avance sobre el culto a Marte indígena en la Península Ibérica», Hom. Montero (supra n. 14), pp. 327-332. Sobre Hércules: M. Oria, "Culto a Hércules en Hispania», Habis 20, 1989, pp. 263-273 (gran concentración en la bética); J. Mangas, «El Hércules gaditano, dios heredero», Hom. Vigil (supra, n. 14), pp. 55-60; R. Atencia - J. Beltrán, «Balance sobre el culto a Hércules en la Bética», Mainake 10, 1988, pp. 125-135, sobre Liber: J. A. Redondo, «Reflexiones sobre la epigrafía de Liben», Norba 8-9, 1987-88, pp. 43-53; O. G. Sanz, "Liber Pater epigráfico en Hispania», ETF ser. II n. 4, 1991, pp. 171-198; J. del Hoyo, "Revisión de los estudios de Liber Pater en la epigrafia hispana», MCV 28, 1992, pp. 65-92 (contiene un total de 26 documentos). Sobre Silvano: A. M. ${ }^{a}$ Vázquez Hoyos, "Algunas consideraciones sobre Silvano en Hispania», ETF ser. II, n. 4, 1991, pp. 107-130. Sobre cultos mistéricos: J. J. Sayas, «Divinidades mistéricas en Lusitania: testimonios y problemas", Rel. Lusitania 1, pp. 143-164; M." A. de Francisco, El culto de Mitra en Hispania, Granada 1989 (recoge sólo 14 inscripciones); J. Mangas, «Pantheus en Hispania», en La Bética en su problemática histórica, Granada 1991, pp. 111-131; J. MangasJ. Vidal, La 'Dea Asturica', Astorga (Cuadernos Municipales I), 1987.

102 M. Mayer, «Rito o literatura en la Cueva Negra», Religio Deorum (supra, nt. 9), pp. 347-356; Id., «La pervivencia de cultos púnicos: el documento de la Cueva Negra (Fortuna, 
Una nueva flaminica provincial de Lusitania ha aparecido en Mérida ${ }^{103}$, la integración de dos fragmentos inéditos con uno ya conocido, todos ellos procedentes de la Bética, permiten conocer un nuevo flamen de esta provincia, que debe fecharse a finales del siglo I o comienzos del II ${ }^{104}$; un fragmento encontrado en Adra completa el texto de CIL II 1979 105: un ignotus de rango ecuestre, también flamen provincial de la Bética, cuya madre - Anulla - ocupó un sacerdocio local e hizo donaciones diversas al municipio. Stylow ha rectificado la lectura de $C I L$ II $2344^{106}$, en la que se honra a $C$. Sempronius Speratus, el más antiguo flamen de la Bética de nombre conocido hasta la fecha.

En un epígrafe antiguo de la provincia de Granada que pasó inadvertido a Hübner, figuran varios miembros de una familia de Anii: el padre era sacerdos Iunonis y uno de los hijos sacerdos Herculis ${ }^{107}$. En Coria del Río (prov. de Sevilla) se encuentra el epitafio de la flaminica Blattia C. $f$. Procla ${ }^{108}$, no recogido en $P B$ : hay otros Blattii con cargos en la misma provincia: uno de ellos, de rango ecuestre, en Hispalis ${ }^{109}$; otro fue uno de los pontifices primi creati Augusto en Italica ${ }^{110}$. La función de la ilipense Agia Ianuaria se designa con el término sacerdotia, de uso poco común ${ }^{111}$. Es muy posible que Sempronia Ga[lla?], que hace diversas donaciones en Arua ${ }^{112}$, sea también una flaminica; no tendría nada de extraño que perteneciera a una familia de negociantes de aceite. La epigrafia de Baelo ha dado un flamen de nombre desconocido y una flaminica de cognomen Procu[la? ${ }^{113}$.

Murcia)», L'Africa Romana 7, Sassari 1990, pp. 695-702; A. U. Stylow, «La Cueva Negra de Fortuna (Murcia), ¿un santuario púnico?», Religio deorum (supra, nt. 9), pp. 449-459.

103 A. Velázquez, Anas 1, 1988, pp. 125-130=AE 1989. 396, cf. HEp. 2, 40: Heluia M. f.. / flamin(ica)... / prouinc(iae) / Lusitaniae / h.s.e.s.t.t.l.

104 Vid. J. González, CILA II.1, nn. 236, 237, 238, que restituye: M. Claudius [...] Patriciensis [...] [fla]men Aug.prouincia[e Baeticae].

105 R. Lázaro, I Encuentro de Cultura Mediterránea, Hom. al P. Tapia, Almería 1986 (publ. 1988), pp. 107-117, cf. HEp. 2, 22 con algunas anotaciones de A. Canto; respecto a este epígrafe puede verse "El progreso...», EMERITA 47, 1, 1979, p. 57 , n. 5 .

$106 M M 28,1987$, nt. 71 , cf. HEp. 2. 328. Otros estudios relacionados con sacerdocios provinciales: J. del Hoyo, Act. VII Congr. Esp. de Est. Clás., Madrid 1989, pp. 171-178; M. Mayer, Fonaments 7, 1988, pp. 223-224=HEp. 2. 673.

${ }_{107}$ ILPGr n. 30, cf. lectura revisada por A. Canto, HEp. 2. 403.

108 V. J. Beltrán Fortes, Baetica 11, 1988, pp. 163-194, n. $4=$ CILA II. 2 n. 593.

109 CILA II 1 n. 20.

110 CILA II $2 \mathrm{n}$. 383. Sobre los pontifices de la Bética vid. mi estudio con este título en Religio deorum, Barcelona 1992, pp. 83-93.

III CILA II 1, Alcalá del Río, n. 289.

112 CILA II 1 n. 233. Respecto a las donaciones hechas en Italica por una flaminica de origen mauritano, $-A E 1983,521-\mathrm{v}$. mi estudio "Relaciones entre Hispania y África...», en L'Africa Romana 8, Sassari 1991, p. 79 ss.

113 J. N. Bonneville-S. Dardaine-P. Le Roux, Epigrafia de Baelo Claudia, n. $16=A E$ $1988 \mathrm{nn}$. 730, 731, es nueva lectura de IRPCádiz $62=H E p .2$. 236; según S. Lefebvre, ZPE 87, 1991, pp. 133-136, la flaminica de cognomen Procu- no es el personaje honrado 
Es llamativo el número de dedicatorias votivas a Júpiter en la zona N.O y en Lusitania, dos de ellas puestas por soldados de la legio VII ${ }^{114}$; se encuentran también otras dedicadas a: Mercurio ${ }^{115}$, Marte ${ }^{116}$, Venus ${ }^{117}$, Diana ${ }^{118}$, Ceres Augusta ${ }^{119}$, Liber y Libera ${ }^{120}$, Hércules ${ }^{121}$, la Victoria ${ }^{122}$ e Isis ${ }^{123}$; quizá

sino un pariente de esa desconocida a quien se pone la estatua; en Epigrafia de Belo n. 17, relectura de IRPCádiz 69c = HEp. 2.237: [flame]n Aug[ustorum], cuyo nombre falta. J. del Hoyo dedica un estudio a Aemilia Paterna, flaminica perpetua: Gerión 7, 1989, pp. 251264. No está clara la lectura de CILA II 2 n. 344, Italica, dedicado a Júpiter por un $M$. Antistius que no se sabe si desempeñó algún sacerdocio. M. G. Schmidt-M. Pastor, en revisión de lecturas de epígrafes en la provincia de Granada, Chiron 19, 1989, pp. 367-386, incluyen la de $C I L$ II $2083=5507$, puesta ob honorem seuiratus; según estos autores, $C I L$ II $2084=5508$ es un fragmento de una inscripción idéntica. Sobre el papel de los Augustales en los municipios, v. J. M. Serrano, RHDFE, 1982.2, pp. 231-240; sobre las dedicatorias ob honorem seuiratus en el conv. Tarraconensis, v. I. Roda, Religio deorum, supra n. 9, pp. 399-404. Sobre antropónimos griegos en la epigrafia religiosa latina de Hispania, v. A. Lozano, Gerión 7, 1989, pp. 207-239.

114 Algunos dentro del grupo publicado por A. Morinho, Brigantia VI 1-3, 1986, pp. 3-36 y VII 1-2, 1987, pp. 101-132 = $A E 1987,603,606,607$; nótese la corrección de lectura en $A E$ 607. A. Rodríguez Colmenero, Aquae Flaviae 1, 1988, n. $541=H E p .3,275$, con sobrenombre indígena de dificil lectura; E. Rivas, Bol. Aur. 18-19, 1988-1989, pp. 103-106 $=H E p$. 3, 276; J. C. Rivas, Bol. Aur. 20-21, 1990-91, pp. 211-220: el autor malinterpreta como doble dedicatoria a Júpiter y a las matres, cuando en realidad se dice ex uoto matris; Id. ibid. pp. 221-232: reaparición de $I R G \mathrm{n} .67 \mathrm{y}$ otra inédita puesta también a Júpiter; J. d'Encarnação, noticia de un ara a I.O.M. en Bracara, Diario do Minho, 22 abril 1992: dedicada por un soldado de la leg. VII G. F.; FE 39.175, en el conu. Emeritensis; J. M. Garcia, Conimbriga 26, 1987, p. 48 ss., n. $4=A E$ 1989, 378; J. Rosco-L. Téllez, I $J M R L$, 1986, p. 135, cf. la corrección de Stylow en HEp. 3. 115; Id., ibid. p. $136=H E p .3 .131$; M. Figuerola, Alcántara 17, 1989, pp. 126-127 n. $1=$ HEp. 3.148; J. A. Redondo-J. Solana, $A E F E$ 8, 1985, pp. 270-272: dos en la provincia de Cáceres, cf. $H E p .1,162=H E p .2$, 212; el ara de procedencia desconocida, conservada en San Vicente de Alcántara (Badajoz), y publicada como inédita en $A E A r q .23,1960$, p. 188 n. 20, debe identificarse con CIL II 606, cf. A. U. Stylow, HEp. 3. 101.

115 CILA II 2, n. 601 (provincia de Sevilla), puesta por un seuir; A. Rodríguez Colmenero-S. Ferrer, Aquae Flauiae I, 1988, n. 536= HEp. 3, 245 (provincia de León); J. Salas-S. Haba, Veleia 4, 1987, pp. 131-132: nueva lectura de $B R A H 44,1904$, p. 121, pero no aceptable, cf. HEp. 2, 220.

116 M. Pérez Reviriego publica una foto de un epigrafe de la provincia de Badajoz, que Stylow interpreta como votivo a Marte, v. HEp. 3, 94.

117 J. Corell, Arse 24, 1989, pp. 845-849; grafito procedente de Sagunto, cf. HEp. 3 , 389.

118 Epigrafia y numismática romanas del monasterio de Silos, Abadía de Silos 1992 (v. supra, apartado 2), n. 4, procedente de la provincia de Orense.

119 A. U. Stylow, Ariadna 5, 1988, pp. 136-138 n. $14=H E p .2,347$ (provincia de Córdoba). Otra a Ceres: P. Guichard-S. Lefebvre, $M C V$ 28, 1992, pp. 165-180: en la provincia de Badajoz, en territorio vecino a Lacimurga (es la misma de la que ya da noticia Stylow, cf. $H E p .3,97$; la parte superior, ya publicada por J. A. Redondo, $A E F E$ 11, 1988, p. 331 n. $7=H E p .1,111)$.

120 J. Rosco-L. Téllez, I JMRL, 1986, pp. 141-142; J. A. Redondo, AEFE 11, 1988, p. 329 , n. 4 dan como nueva una ya conocida, cf. $H E p$. 3, 136; con referencia a $H E p$. 2, 206, J. L. Melena, Veleia 7, 1990, pp. 147-154, hace notar que no existe la nueva divinidad que se supone, sino que se trata de un epígrafe puesto a $L($ ibera $)$ et $L($ ibero). 
proceda de la Bética una inscripción griega bajo una escultura de Cibeles ${ }^{124}$. En Pontes (La Coruña) se ha hallado un epígrafe puesto ex interpretatione oraculi Clari Apollinis, muy similar a otros extendidos por distintas regiones del Imperio, fechables a comienzos del s. III ${ }^{125}$. Salus, Tutela y otras divinidades menores, protectoras de diversos lugares, están también representadas en nuevos hallazgos ${ }^{126}$.

\section{Ciudades y administración local}

Los estudios sobre las ciudades y su organización conocen en estos últimos años un momento floreciente. La obra titulada La ciudad hispano-romana constituye una visión panorámica e incluye lo más esencial de la bibliografía sobre el tema ${ }^{127}$. Para una evaluación global del avance que representa en nuestros conocimientos sobre la romanización de la Península la obra de Alföldy Römischen Städtewesen auf der Neukastilischen Hochebene, puede verse la recensión de M. Mayer ${ }^{128}$. Estudios monográficos de diversas ciudades

121 J. Corell, Alba 4, 1989, pp. 7-8 = HEp. 3, 385 (provincia de Valencia).

122 C. Barrantes-S. Paniagua, Veleia 4, 1987, pp. 141-143 =HEp. 2, 221. A la Fortuna Augusta está dedicado un epígrafe nuevo de Sabora, en la Bética: R. Atencia, Baetica 10, 1987 , pp. $139-159$, n. 7.

${ }^{123} \mathrm{~J}$. N. Bonneville-S. Dardaine-P. Le Roux, Belo V n. $1=H E p .2$, 227: placa de plomo con una larga súplica a Isis, cf. $A E 1988,727$; Id. ibid. n. 2, relectura de $M C V 20,1984$, pp. 484-485; J. R. Corzo-M. Toscano, Italica: excavación en el teatro, Sevilla 1991 (mem. mecanografiada), vol. II 2, p. 88 ss., nn. 2, 3, 4, con plantae pedum; A. Canto interpreta como Dea Caelestis la inscripción bajo una cabeza femenina hallada en la provincia de Córdoba, v. HEp. 3, 161: llega a la conclusión, quizá algo precipitada, de que el santuario estaría dedicado a la diosa sincrética Isis Caelestis.

124 P. Bádenas, Bol. Mus. Arq. Nac. 1-2, 1987, p. 12 ss.

125 S. Montero, Gerión, Anejos 2, 1989, pp. 357-364=HEp. 3, 172.

126 A Salus: A. González Cordero et alii, Alcántara 8, 1986, pp. 65-77 n. 13; J. A. Redondo, $A E F E 11,1988$, p. 328, n. $3=H E p .3,135$. A Tutela: «Epigrafia y Numismática romanas del Monasterio de Silos" (supra, n. 127), n. 2 (provincia de León); A. G. Linares-N. Santos Yanguas, Mem. de H. ${ }^{a}$ Antigua 10, 1989, pp. 151-162: primera inscripción de Tutela en la región asturiana; CILA II 1, n. 265, Villanueva del Río (Sevilla). A los Lares Viales: J. Corell, Fonaments 7, 1988, pp. 197-198 = HEp. 2. 16, con la fórmula ex somnio; J. d'Encarnação, Trab. de Arq. do Sul 1, 1986, pp. 105-106 = HEp. 3. 487: ya conocido, pero ausente en los grandes repertorios; Stylow en HEp. 2. 223: el epigrafe publicado en Exc. Arq. 1, 1988, p. 240 está dedicado a Lares Viales. A las ninfas: J. Mangas et alii, Hisp. Ant. 16, 1992, p. 252 y ss., n. 8 (provincia de Toledo); A. Rodríguez Colmenero-S. Ferrer, Aquae Flauiae 1, 1988, n. $535=H E p$. 3, 490. A los Genii: CIL II 618, reencontrada, v. HEp. 3. 141; en $A E 1987,611$ se corrige J. Mangas-J. Vidal, Cuad. Municip. 1, 1987, pp. 7-15: parece ser una dedicatoria al genius Asturicensium; la palabra genius se lee en la base de una columnilla de Italica: A. Blanco-P. León, Traianeum de Italica, Sevilla 1988, p. 117, nt. 8 Di(is) et dea(bus) conuen(tus) deorum se lee en J. González Echegaray-J. L. Casado, Altamira 42, 1975-80, pp. 239-240, n. $2=H E p ., 3,150$, donde Mangas corrige el nombre de la dedicante en: Fla(uia) Cent(-i/-anif.) Ana: entiendo 
hispanas encontramos en la revista italiana Dialoghi di Archeologia ${ }^{129}$. Otra serie de estudios, que ponen en relación ciudades y cultos, encontramos en la obra Religio deorum ${ }^{130}$; varias reuniones internacionales se han ocupado, como ya dijimos más arriba, de la organización de las ciudades ${ }^{131}$. Ha visto la luz póstumamente la tercera parte de la obra de Tovar, dedicada a la provincia Tarraconense ${ }^{132}$.

M. A. Marín se ha ocupado de la creación de ciuitates de derecho latino en el siglo I a. C., especialmente en la Ulterior ${ }^{133}$; otros trabajos contemplan la municipalización de la Bética bajo Vespasiano y Domiciano ${ }^{134}$. A. M. Canto

que debe leerse Flauia Centiana; sobre la epigrafia votiva de Conimbriga, v. J. M. García, Conimbriga 10, 1987, pp. 39-59. A. M. ${ }^{a}$ Vázquez publica en Dianium 5, 1990, pp. 143-166 un estudio que incluye las dedicatorias a Successus, Fatum, y Fortuna.

127 J. M. Abascal-U. Espinosa, La ciudad hispono-romana, Logroño 1989. Están en prensa las actas del Coloquio Ciudad y comunidad civica en Hispania en los s. II y III a. C., Coloquio Casa de Velázquez, C.S.I.C., Madrid 1990.

${ }^{128}$ M. Mayer, «Nueva luz sobre la romanización de Hispania: un modelo metodológico», Journal of Roman Archaeology 5, 1992, pp. 374-377.

129 Dialoghi di Archeologia terza ser. 10, 1992. Otros estudios: S. Ordóñez, Colonia Augusta Firma Astigi, Écija 1988; U. Espinosa, Vareia. Enclave romano en el valle del Ebro, Logroño 1990. J. M. Blázquez, "La epigrafia de Cástulo: consideraciones históricas», Nuevos estudios sobre la romanización, Madrid 1989, cap. VII, p. 293 ss.; M. Pastor, «Société, religión et epigraphie dans le municipium de Castulo", Latomus 48, 1989, p. 623 ss. Otros autores hacen anotaciones breves: G. Arias, "Laminio, Sisapone y Titulcia en Alfoldy", El Miliario 25, 1990, pp. 5-6; A. Canto, HEp. 2.267, precisa que la ciudad de la que se habla en $A E A r q .60,1987$, pp. 237-250 se llamaba Saepo, no Vsaepo y se localiza a unos $40 \mathrm{Kms}$. al N. de Oluera (Cádiz): esta ciudad, sin epíteto, cuyos ciudadanos se inscriben en la Quirina, debe distinguirse del municipium Victor Saeponensium al que corresponde la Galeria.

130 Cf. supra, n. 9: G. Alfoldy, "Tarraco y la Hispania romana: cultos y sociedad", pp. 7-26; J. d'Encarnação, "Culto e sociedade na Salacia romana», pp. 161-169; C. González Román, "Elite social y religión en la Colonia Augusta Gemella Tucci», pp. 283-294; M. Pastor, «Religión y culto en el Municipium Florentinum Iliberritanum», pp. 369-388; J. L. Ramírez Sádaba, «Panorámica religiosa de Augusta Emerita», pp. 389-398.

131 Cf. supra, n. 7. El trabajo de J. J. Ramírez Sádaba, "Villas de Lusitania», pp. 293311 , es un intento de reconstruir la estructura demográfica de Emerita a través de la epigrafia. Otros estudios incluidos: P. Le Roux, «Les villes de statut municipal en Lusitanie Romaine», pp. 35-49; A. Tranoy, «L'organisation urbaine dans le conu. Scallabitanus», pp. 11-20; J. G. Gorges, "Villes et villas de Lusitanie», pp. 91-113; J. d'Alarçâo, «Identificaçâo das cidades de Lusitania portuguesa e dos seus territorios», pp. 21-34.

${ }^{132}$ A. Tovar, Iberische Landeskunde II.3 Tarraconensis, Baden-Baden 1989 (en espaกิol).

${ }_{133}$ M." A. Marín, Emigración y municipalización en la Historia republicana, Granada 1988. M. Mayer trata sobre "Plinio el Viejo y las ciudades de la Bética», Estudios sobre Urso, ed. J. González, Sevilla 1989, pp. 303-333.

134 V. el trabajo de Nony en Recherches épigraphiques, ed. B. Remy (cf. REL 65, 1987, p. 382); A. U. Stylow, Ius Latii y derechos latinos en Hispania, vol IX, H.a Antigua, col. Studia Historica, Salamanca 1992, estudia el status y la localización de las ciudades de la Baeturia Turdulorum que parecen haber alcanzado el rango de municipio de derecho latino en época flavia; en este estudio se identifica el municipio correspondiente a la actual 
ha replanteado cuestiones referentes a la fundación de colonias ${ }^{135}$ : propone como fundador de Corduba no al legado proconsular de la Citerior en 152-151 a. C., como veníamos haciendo, sino al homónimo, fallido heredero de Augusto, muerto en Baiae en el a. 23 a. C.; la ciudad habría sido fundada como colonia latina hacia el a. 200 a. C., con asignación de sus ciudadanos a la tribu Sergia, y no sería elevada al rango de colonia romana hasta época augustea, en la que adquiriría el sobrenombre de Patricia, y se produciría la adscripción de sus ciudadanos a la tribu Galeria: hipótesis brillante, aunque por ahora no puede probarse ${ }^{136}$. Con apoyo en una nueva inscripción de Clunia, Haley afirma que Galba no sólo elevó esta última ciudad a la categoría de colonia, sino que asentó allí una colonia de veteranos ${ }^{137}$. Otros autores tratan sobre el estatuto jurídico de Valencia ${ }^{138}$, Cádiz ${ }^{139}$, Jerez ${ }^{140}$, Asido y Astigi ${ }^{141}$. Ha

Azuaga como municipio Flauium, no Iulium como se venía pensando. Sobre la municipalización del conuentus Asturicensis, J. Santos Yanguas, Astorga Romana, Astorga 1986, pp. 103-119.

135 A. M." Canto, "Colonia Patricia Corduba: nuevas hipótesis sobre su fundación y nombre», Latomus 50, 1991, pp. 846-857; Colonia Iulia Augusta Emerita: consideraciones en torno a su fundación y territorio», Gerión 7, 1989, pp. 149-206, cf. $A E$ 1989, 397; «Las tres fundaciones de Augusta Emerita», Actas del Coloquio Staatbild und Ideologie, Munich 1990, p. 289 ss. Sobre el territorio de Augusta Emerita, v. también: J. M. Fernández Corrales, $X I X C N A$, pp. 889-898, y J. M. Alvarez Martínez, Hom. S. de los Santos, p. $188=$ $H E p .2,43$; un terminus augustalis que figuraba ya en el Diccionario de Madoz, pero estaba perdido, fijaba un enclave emeritense entre los territorios de Contributa y Curiga por el sur y Nertobriga Seria Fama Iulia por el Occidente; por otra parte, A. T. Fear, Gerión 9, 1991, pp. 151-162, estudia la localización, status e interrelación de Contributa Iulia, Ugulturnia y Curiga.

${ }_{136} \mathrm{La}$ adscripción a la Galería habla más bien de una fundación algo más antigua: cuando todavía era Octaviano, v. mi artículo "La tribu Galeria en Hispania», en Estudios sobre la Tabula Siarensis, Madrid 1988, pp. 233-241.

137 E. W. Haley, ZPE 9, 1992, PP. 159-164, apoyado en $A E 1988,806$, donde figura un veterano de origen caesaraugustano.

138 M." J. Pena, «Consideraciones sobre el estatuto jurídico de Valencia», Saguntum 22, 1989, pp. 303-318: sobre los resultados de la arqueología, llega a la conclusión de un reestablecimiento augusteo - en todo caso julio-claudio- de la ciudad, con asentamiento de veteranos; pero esto no asegura que tuviera estatuto colonial en época imperial. Llama la atención sobre la exiguas dimensiones y falta de monumentalidad de la ciudad.

${ }_{139}$ M." P. García-Bellido, "¿Colonia Augusta Gaditana??», AEArq. 61, 1988, pp. 324335: sobre la leyenda de una moneda de Gades, plantea la espinosa cuestión de la elevación de esta ciudad a la categoría de colonia por parte de Augusto; a favor de la hipótesis estaría la contramarca sobre un as de Gades (F. J. Blanco, ibid., pp. 335-337), con la leyenda Col., posterior a la emisión de la moneda, que se fecha entre a. 45 a. C. y el cambio de era.

140 A. Padilla, Habis 20,1989, pp. 185-190: propone leer en CIL II 1305 p(opulus) m(unicipii) C(eretani), en lugar del admitido m(unicipi) C(aesarini); a idéntica conclusión he llegado yo misma, independientemente: v. «¿Jerez, municipium Ceretanum?», Excerpta Philologica A. Holgado sacra, I, Cádiz, 1991, pp. 155-158.

141 A. Padilla, Habis 21, 1990, pp. 241-258: estudia, a través de una perspectiva social, la transferencia de poder de Gades a Asido; sobre el cambio de status de Asido, ya había escrito este mismo autor (v. Habis 16, 1985, pp. 307-327); primero municipio latino con 
aparecido una monografia sobre el famoso epígrafe del Puente de Alcántara, datado en época de Trajano ${ }^{142}$.

M. Zahrmt ${ }^{143}$ propone la consideración de Ilugo como municipio de fundación adrianea, basándose en una reconstrucción de CIL II 3239: son varias las razones que aconsejan reservas frente a esta propuesta. Tenemos ahora el primer testimonio epigráfico del ordo Augurinorum Segidensium ${ }^{144}$. Un nuevo municipio de nombre Elaisio, parece ofrecernos una pieza encontrada en Botorrita ${ }^{145}$. La condición municipal de Cauca queda documentada en la tabula de Montealegre (v. supra, apartado 3, n. 47).

Varios epígrafes nuevos dan a conocer la origo de diferentes individuos ${ }^{146}$; en una inscripción nueva de Axati (Lora del Río, Sevilla) aparece el término conuicini ${ }^{147}$.

En el apartado de cargos locales debe mencionarse en primer lugar la aparición del libro de L. A. Curchin, The Local Magistrates of Roman Spain ${ }^{148}$. S. Dardaine ha dedicado también atención al ámbito de los notables municipales y del evergetismo ${ }^{149}$. Otros autores se han ocupado de las elites municipales en la región N. E. de la Citerior ${ }^{149}$; Schulze-Oben ha dedicado una monografia a los libertos en las ciudades hispanas ${ }^{150}$.

Un epígrafe de Singilia Barba, publicado en 1988, proporciona valiosa información sobre la munificencia del duouir M. Valerius M. f. M. n. G. pron.,

César, y más tarde - hacia el a. 15/14 a. C.- deductio colonial, G. Chic, Tres estudios sobre la Colonia Firma Astigi, Sevilla 1988.

142 J. Liz Guiral, Madrid 1988, cf. $A E$ 1988. 700.

143 H. Zahrmt, "Ein hadrianisches Municipium in der Hispania Tarraconensis?», ZPE 79, 1989, pp. 173-176.

144 A. U. Stylow, Ariadna 5, 1988, n. $14=2,348$ : inscripción acéfala, dedicada a un personaje de la ciudad cuyo cognomen era Maximus. El mismo autor $(H E p .3,97)$ da noticia del hallazgo de la parte inferior de un epígrafe de la provincia de Badajoz $(H E p .1,111)$, en el que se lee: icanis: este epígrafe, completo, ha sido publicado como inédito por $P$. Guichard-S. Lefebvre, MCV 28, 1992, pp. 165-180, cf. supra, n. 119.

145 F. Beltrán, EJR, pp. 362 s., cf. $A E$ 1989, 470 y HEp, 3. 414.

$146 \mathrm{La}$ lectura uxamensis en J. M. Velasco-V. Martínez, Wad-ad-Hayara 13, 1986, pp. 379-382 es mala, cf. A. U. Stylow, HEp. 3, 191; J. González, CILA I, n. 22: un olisiponense en Alájar (Huelva), cf. A. M." Canto, HEp. 3. 192 que corrige la lectura del nomen: M. Figuerola, Alcántara 17, 1989, pp. 131-132, n. 7: Campegiensis et Voliseni(?), cf. HEp. 3. 147; A. Corte-J d'Encarnação, FE 34, n. 153: oppidanus Lauriensis.

${ }_{47}$ G. Chic, Rev de Est. Locales 4, 1993, pp. 7-13. El autor sugiere cierta relación con la inscripción de las centurias de Arua, de las que era patrono Q. Fuluius Carisianus.

148 Toronto 1990. Reseña mía en EMERITA 61, 2, 1993.

149 S. Dardaine, Ktema 11, 1986, pp. 291-302: de un total de 28 inscripciones que recogen fenómenos de evergetismo, 8 corresponden a la Península Ibérica: Id., "Honneurs funèbres et notables municipaux dans l'epigraphie de la Bétique", Habis 23, 1992, pp. 139-151.

149a G. Fabre-M. Mayer-I. Rodá, MCV 102, 2, 1990, pp. 525-539.

150 H. Schulze-Oben, Freigelassene in den Städten des römischen Hispanien, Bonn 1989. 
quir. Proculinus: el magistrado, que pertenece a la cuarta generación de ciudadanos romanos en su familia, ofreció - entre otras liberalidades - un reparto de aceite populum uniuersum in municipio habitantem et incolas; el epígrafe, fechado en el a. 109, ha despertado el interés de varios estudiosos ${ }^{151}$. Es muy probable que $M$. Trahius $C$.f., nombrado en un mosaico de Italica, desempeñara una magistratura local ${ }^{151 a}$.

Un epígrafe incompleto procedente del Traianeum de Italica, contiene una dedicatoria $o b$ honorem, en la que el culto a Júpiter aparece unido al del Genio de la colonia ${ }^{152}$, puede que el dedicante sea un flamen del culto imperial.

Alföldy ha reconstruido la inscripción de acueducto de Segovia: responde a una restauración hecha bajo Trajano y contiene los nombres de los duouiri que se encargaron de la obra ${ }^{153}$; un epígrafe incompleto de Córdoba da parte de la onomástica de un Iluir de la Colonia 154; en esta misma ciudad, un Cornelius, que fue aedilis y lluir, dejó constancia de sus liberalidades: lacus siliceos, effigies aheneas ${ }^{155}$, en un epígrafe monumental de Baelo quizá otro Cornelio dedicó una basílica o un macellum ${ }^{156}$; probablemente sería un magistrado de la ciudad; otra inscripción incompleta de la provincia de Huelva proporciona parte de la onomástica de dos ediles de un municipio flavio ${ }^{157}$; una moneda inédita de Tiberio, conservada en el Instituto Valencia de D. Juan, da los nombres abreviados de dos magistrados de Bilbilis ${ }^{158}$; un decurio mentesanus figura en inscripción funeraria puesta por los libertos del personaje ${ }^{159}$. Otras varias inscripciones proporcionan nuevas menciones de tribus ${ }^{160}$.

151 E. Serrano-P. Rodríguez Oliva, "Tres nuevas inscripciones de Singilia Barba», Baetica 11, 1988, pp. 237-256, n. $1=A E 1989,420$; vid. $H E p, 2,469$; R. Atencia-A. de Luque, Mainake 11, 1989-90, pp. 171-180; P. Le Roux, "Cité et culture muncipale en Bétique sous Trajan", Ktema 12, 1987, pp. 271-184.

Isla A. Caballos, Habis 18-19, 1987-88 [1989], pp. 299-313 = AE 1988. 707. Una primera noticia fue dada por J. Gil en Gerión, 4, 1986, pp. 325-327 $=A E$ 1987. 494. Se piensa que el personaje puede ser antepasado de Trajano por línea materna, v. A. Caballos, $S H$ (supra, n. 69).

152 A. Blanco, Traianeum de Italica, Sevilla 1988: el epígrafe que mencionamos es uno de los 3 inéditos, cf. $A E 1988,708-710$; v. HEp. 2. 630, con ligeras variantes de lectura.

153 G. Alfoldy, ZPE 94, 1992, pp. 231-248. Otras magistraturas locales en epígrafes reconstruidos por Alfoldy: Stadtewesen..., p. 87, cf. $A E$ 1987, 666-667.

154 A. U. Stylow, Ariadna 5, 1988, pp. 145-149 = HEp. 2, 296.

155 J. M. Bermúdez et alii, An. Arq. Cordobesa 2, 1991, pp. 291-308: dos epígrafes incompletos, con texto similar, uno de ellos quizá con mención de Aq[ua Augusta].

156 Belo V n. $19=$ HEp. 2, 238.

157 J. González, CILA I, 1989, n. $21=H E p .3,210$.

158 C. Blázquez Cerrato, Kalathos 7-8, 1987-88, pp. 115-122. El autor lee un nomen abreviado $M A L$; quizá sea preferible leer $M A E$ (CIVS).

159 G. Guerrero, BIEG 34, 1988, pp. 54-55; un d[ecurio] Patriciensis cree ver E. W. Haley, Foreigners..., p. 229 , n. $325=H E p$. 3, 166, nueva lectura de CIL II 2245. S. Or- 
Un epigrafe de Ilipa parece confirmar que esta ciudad tenía como sobrenombre Ilia, como ya propuso Thouvenot, sin éxito ${ }^{161}$. Tenemos la primera mención epigráfica del ordo Augurinorum Segidensium, correspondiente a Palma del Río: la inscripción estaba dedicada a un Maxumus al que la ciudad concede honores: statuam, locum sepulturae, funeris impensam ${ }^{162}$.

Son relativamente abundantes las discusiones en torno a la localización de ciudades antiguas ${ }^{163}$; especial interés presenta la inscripción en bronce, datada en época augustea, que describe un territorio centuriado, quizá el correspondiente a la antigua $V c c u b i$, en la Bética ${ }^{164}$.

dóñez, Colonia Augusta Firma Astigi, Écija 1988, p. 165, da el nombre de un decurión de esta ciudad, v. HEp. 3, 341.

160 J. Salas-S. Haba, Veleia 4, 1987, pp. 134-138=HEp. 2. 32: epígrafe de la Colonia Metellinensis con tribu Sergia; M. G. Schmidt-M. Pastor, Chiron 19, 1989, 1989, pp. 385386 n. 5: nueva lectura de CPUGR 10,1985, pp. 463-468, que supone el tercer testimonio de tribu Pupinia en Acci, cf. HEp. 1, 348. J. d'Encarnação, Cidade de Evora 69-70, 198687 , presenta un evorense, patrono de un subsellarius, inscrito en la Galería (otro subsellarius encontramos en CIL VI 6055). G. Alfoldy, Städtewesen..., cf. AE 1987. 664, rehabilita CIL II $381^{\circ}$, con un magistrado de Segobriga inscrito en la Galeria, tribu que tienen otros magistrados de esta ciudad, v. Wiegels, Tribusinschriften..., p. 134; Id., ibid., p. 76, n. 240 : nueva lectura de CIL II 3124: un ciudadano Valeriensis de la Galeria; Id., ibid., reconstruye CIL II 3126, que nos daría el primer Pompaelonensis con tribu documentada, pero esta reconstrucción que supone la Galeria no es apoyo suficiente para establecer hipótesis sobre la concesión de estatuto privilegiado a Pompaelo con anterioridad a Vespasiano. Parece insegura la restitución de Lázaro - [Quiri]na en Hom. Tapia, p. $124=H E p .2$, 23; es más que dudosa la lectura Q(uirina tribu) en inscripción de Luzaga publicada por J. M. Velasco-V. Martínez, Wad-al-Hayara 13, 1986, p. 382 ss., cf. HEp. 3, 190; probablemente la Q. conservada formaba parte de la filiación; leo: [.]tus [Bo]utius Quinti[us] Q(uinti) V/[alen]ti fi/ [li]us/s.t.t.l. A. Donati publica reseña del libro de Wiegels en Epigraphica 52, 1990 , p. 268.

161 CILA II 1, n. 289; el editor no comenta nada acerca del sobrenombre. Los manuscritos de Plinio dan Ilipa cognomine Ilpa, que los editores corrigen en Ilipa cognomine Magna, apoyados en Ptol. II 4, 10 y siguiendo a Schulten, cf. A. Tovar, Iberische Laudeskunde, I, p. 162.

162 A. U. Stylow, Ariadna 5, 1988, n. $14=H E p .2,348$, J. del Hoyo, ETF II 2, 1989 , p. 89, restituye el texto perdido en CIL II 1191, por comparación con $H A E p$. 1027; A. M. ${ }^{\text {a }}$ Canto en HEp. 3, 336 discute la interpretación dada por del Hoyo a la expresión adiectis specularibus et uelis.

163 M. J. Pérez Agorreta, "En torno a la localización de Aracilus (Navarra)», Hisp. Ant. 14, 1990, pp. 135 ss.; Ead.- M. Unzu, «Notas sobre la posible localización de Iturissa (Espinal, Navarra)", I Congr. H. ${ }^{a}$ Gral. de Navarra, Pamplona 1987, p. 553 ss.; J. Gómez Pantoja, «Castillos en el Duero», Gerión 7, 1989, pp. 241-249: contra la reciente opinión de la existencia de un municipio latino en el lugar de la actual San Esteban de Gormaz (Soria); Id., "Una nota de topografia antigua aragonesa», Kalathos 9-10, 1989-90, pp. 255258: sobre la localización de Leonica; L. Pérez Vilatela, "La ubicación de Osicerda», El Miliario 26, 1990, pp. 8-9; C. G. Cravioto, «De nuevo sobre la localización de Vesci», El Miliario 26, 1990, pp. 3-4; R. Atencia, Baetica 10, 1987, pp. 139-159: sobre la localización de Sabora; D. Sedeño, «Tingentera: un problema de la Hispania Antigua», CAN 19, 1, pp. 927-933.

164 P. Sáez Fernández, Habis 21, 1990, pp. 205-228; foto en Habis 22, 1991, p. 417. 


\section{Epigrafia prerromana; cultos y onomástica indigenas}

Se siguen intentando interpretaciones del primer bronce de Botorrita: Hamp ha creído ver en una de sus secuencias una fórmula correspondiente a una lex sacra ${ }^{165}$; un nuevo epígrafe en alfabeto ibérico, encontrado en un mosaico de Andelo (prov. Navarra), presenta cierta semejanza con el ya conocido de Caminreal (prov. Teruel) ${ }^{166}$. Algunas otras inscripciones ibéricas se han encontrado en la costa levantina ${ }^{167}$. J. A. Correa ha recogido en un estudio monográfico la epigrafia tartesia conocida ${ }^{168}$. En el volumen titulado Religio deorum se contienen varios estudios sobre cultos prerromanos ${ }^{169}$.

Blázquez ofrece una puesta al día de las religiones primitivas de Hispania ${ }^{170}$; J. d'Encarnaçao presenta un balance sobre el estudio de las divinidades indígenas de Lusitania ${ }^{171}$; en el II Congreso General de Historia de Navarra presenté un trabajo de conjunto sobre la onomástica en las inscripciones romanas de esta región, donde se estudian varios teónimos indígenas 172.

165 Hablo del "primer» bronce de Botorrita, porque en la primavera de 1993 se ha hallado un segundo bronce en escritura ibérica, de gran tamaño, aún inédito. Respecto al bronce conocido, me refiero a E. P. Hamp, Veleia 7, 1990, pp. 165-166, que cita a J. F. Eska, Towards an Interpretation of the Hispano-Celtic Inscription of Botorrita, Innsbruck 1989, pp. 14-16.

166 V. la noticia del hallazgo en M." A. Mezquíriz, Tr. Arq. Nav. 10, 1991-92, pp. $365-$ 366; J. Untermann está estudiando la pieza. Un nuevo antropónimo parece registrar un grafito en signario ibérico en cerámica procedente de Grachurris: J. A. Hernández-J. Núnez, Veleia 6, 1989, pp. 201-214.

167 D. Fletcher Valls-L. Silgo, Arse 26, 1991; F. Roca, Arse 24, 1989, p. 837 ss.; L. Silgo, ibid., pp. 833-836.

168 J. A. Correa, "La epigrafia tartesia», Andalusien zwischen Vorgeschichte und Mittelelalter, Köln 1992, pp. 75-114. Este autor había publicado recientemente en AEArq. 61, 1988 , pp. 197-200, un epígrafe tartesio del S. de Portugal; avanza ya en este trabajo el posible carácter celta (ide. occidental) de la lengua de estos epigrafes: bien entendido que celta en la Península no quiere decir siempre celtíbero o celtiberizado.

169 Supra, n. 9: J. González, Divinidades preromanas en Andalucia, pp. 271-282; F. Marco, La individualización del espacio sagrado: testimonios culturales en el N.O. hispánico, pp. 317-324; F. Beltrán, Culto a los lares y grupos de parentesco en la Hispania indoeuropea, pp. 59-71.

170 J. M." Blázquez-M. a P. García Gelabert, ETF ser. II I (Hom. Ripoll), 1988, pp. 153-183.

171 Conimbriga 26, 1987, pp. 5-37 = $A E$ 1986.362. V. además: Id., "Religiåo e cultura na epigrafia de Liberalitas Iulia», Villes de Lusitanie (supra, n. 7), pp. 233-253; sobre la epigrafia de Viseu: Id., I Col. Arq. de Viseu, Viseu 1989, pp. 315-323 y J. L. Vaz, ibid. pp. 325-331; F. Díez de Velasco: «Sobre las divinidades indigenas de las aguas termales en el Occidente hispano", Larouco 1, 1991, pp. 53-59; J. L. Ramírez Sádaba, Teónimo y antropónimos nuevos en la provincia de Lusitania y zonas próximas, Actas del V Col. sobre Lenguas y Culturas prerrománicas de las Península Ibérica, Colonia 1989, publicado en Salamanca 1992, pp. 425-444; Id., "Interpretatio romana», ibid., pp. 281-287.

172 C. Castillo, Anejos PV 14, Pamplona 1994, pp. 117-133. Contiene además una lista de los nombres personales que se encuentran en este conjunto epigráfico, cf. $A E 1989$, 456-461. 
No cesan de aparecer epígrafes en los que se documentan nuevos teónimos ${ }^{173}$, o bien se alude a divinidades ya conocidas, a veces con epítetos nuevos ${ }^{174}$; en Alcuéstar (prov. Cáceres) debió de existir un templo de Ataecina, a juzgar por el conjunto de votivas dedicadas a esta diosa cuyo nombre se presenta con diversas variantes gráficas ${ }^{175}$.

Los topónimos en -briga conocidos en Hispania son ahora ochenta y nueve ${ }^{176}$. El número de grupos suprafamiliares mencionados mediante genitivo plural se ha acrecentado: merece especial mención en este apartado el grupo de inscripciones procedentes de la región Carpetana publicado por Stylow ${ }^{177}$;

${ }^{173}$ HEp. 2, 189 y 190 (Cáceres). Sobre $A E 1986,319=H E p .1$, 94, v. Stylow en HEp. 2, 31: no hay tal divinidad Denna, sino Deanae, variante vulgar de Diana. Otras divinidades nuevas: A. Fernández Galiano-J. A. Arenas, Wad-al Hajara 15, 1988, pp. 371376, v. HEp. 3, 189; A. Rodríguez Colmenero, Larouco 1, 1991, p. 165; G. Rueda, Gerión 6, 1988, pp. 273-279; A. Saenz de Buruaga, EAA 16, 1988, p. 554, cf. HEp. 3, 5.

174 J. Rodríguez, Bol. Aur. 20-21, 1990-1991, pp. 205-210: lari Ocaelaedo; H. GimenoG. Vargas, FE 42. 188: Endovelico $=H E p .3,477$; F. Sande-J. d'Encarnação, $F E$ 40. 179 = Brigantia 11, 3-4, 1991, pp. 121-125; Bandu Vordeaeco; J. L. Ines Vaz, FE 35. 157: Albucelaincus; FE 38. 174: Quangeius Turicaecus, protector de los Turicaei (nombre que se documenta por vez primera); F. Gómez et alii, Baetica 11, 1988, pp. 211-213: divinidad cuyo nombre acaba en - mma; $M$. M. Alves Dias, Inventario e defesa do patrimonio, Lisboa 1991, pp. 361-365: relectura de CIL II 5247; J. Salas et alii, HA 13, 1986-89, pp. 7-20= AE 1989, 398-399 = HEp. 3, 119-121: Apulusaecus, nuevo epiteto de Bandua; J. C. Rivas, $C E G, 104,1991$, p. 35 : corrige $C I L$ II $2515=I R G$ IV. 86 , no existe el supuesto Bandueaetobrigus. G. Rueda, Gerión 6, 1988, pp. 273-275: Bletis, relacionado con el topónimo Bletisame, cf. HEp. 2, 206, corregido por J. L. Melena, Veleia 7, 1990, pp. 147-154: no hay tal divinidad (v. supra, n. 120); J. C. Rivas, Bol. Aur. 18-19, 1988-89, pp. 95-102: Ariounis Mincosegaligis, cf. HEp. 3, 279. F. Arias, BMPL 2, 1989, pp. 229-232 = HEp. 3, 46: a Nouia, con lectura dudosa; J. M. Domínguez, Norba 8-9, 1987-88, pp. 33-41: votiva con datos sobre una danza prerromana; J. Salas, Veleia 4, 1987, pp. 127-133 e HEp. 2, 204: votiva en la provincia de Cáceres, con lectura dudosa.

175 L. Caballero-J. Rosco, Extr. Arq. 1, 1988, pp. 246-249, cf. HEp. 2, 196-200. Una nueva evidencia del culto a esta divinidad: R. López Melero, Rel. Lusitania 1, pp. 93-112.

176 M." L. Albertos, Veleia 7, 1990, pp. 131-146: ampliación de las recogidas por Untermann en 1961; la distribución geográfica no difiere sensiblemente de la ya conocida.

177 Chiron 20, 1990, pp. 307-344; además: J. Mangas et alii, HA 16, 1992, n. 3: Quranum, n. 12: Pilonicorum. En la epigrafia de Guadalajara: Belainocum, Abboiocum, Nissi[cum], Segossoq[um], Cossouqum, Melmaniq[um], Madugenicum, v. AE 1987, 621, 623, 624, 628, 642, 653. En Segovia: Cantabr[e]cum Moueg[um], vid. J. Santos Yanguas-A. L. Hoces, Veleia 6, 1989, pp. 215-234, nn. 2 y 4; E. W. Haley, Foreigners in Roman Imperial Spain, Nueva York 1986, p. 72: Aelcecum (según lectura inédita de Knapp) y pp. 25, 262: A [m]minicum, cf. HEp. 3, 26-27; entre los astures: Cilurginorum, C. Fdez, Ochoa-D. Pérez, CuPAUAM 17, 1990, pp. 255-265; parece que debe interpretarse también como gentilidad: Ateroecon. Sobre un verraco, G. López Monteagudo, Esculturas zoomoofas celtas de la Península Ibérica, Madrid 1989, n. 126; H. Gimeno, Faventia 11, 2, 1989, pp. 23-28: inédita, en un ms. de la Biblioteca Nacional, Elesicainum, quizás relacionado con el antropónimo Elaesus; Id., Veleia 6, 1989, p. $238=A E 1989,361$ c): en otro ms., un epígrafe procedente de Tafalla, de lectura poco cierta; J. M. Abascal, STH 6, 1988, pp. 133-134: revisión de $A E 1981,556=H E p .2,414$, Bela[n]ogum, quizá relacionada con el sobre- 
otras hacen referencia a castella ${ }^{178}$. Ha pasado inadvertido hasta ahora un epígrafe de Mérida, publicado por Holgado en $1980^{179}$, en el que el elemento onomástico Cobelcus, que sigue a la filiación, debe interpretarse a mi entender como indicador de pertenencia a una gentilidad o grupo similar. En Ordunetsis, adjetivo referido a un veterano de la legio II Augusta documentado en Navarra, se ha visto un nombre de origen ibérico, pero con grafia que refleja fonética vascona ${ }^{180}$; el nombre Agelean(ius) que figura en un exvoto del santuario ibérico de Torreparedones (Córdoba) parece a A. M. Canto de origen indoeuropeo ${ }^{181}$.

\section{Vias y miliarios}

El número triple de la nueva serie de El Miliario Extravagante, correspondiente a noviembre de 1992, contiene un catálogo de vías romanas de Hispania, un índice alfabético de la segunda época, y un sumario sistemático-geográfico; a ello remitimos para todo lo aparecido en la segunda época de esta publicación periódica, que se autodenomina «boletín intermitente».

Como ya indicamos más arriba, las vías romanas en Hispania han sido tema central de Symposia ${ }^{182}$; es ésta una cuestión a la que continúa dedicando su atención P. Silliéres, que ha interpretado la escasez de vías romanas en la zona meridional como consecuencia de que para los transportes se utilizaba vía fluvial o maritima ${ }^{183}$; diversos autores estudian las comunicaciones en diferentes regiones de la Península ${ }^{184}$; desde otro punto de vista se ha tratado el

nombre Belaisca que lleva la ciudad de Contrebia; en $A E 1988,805$ se sugiere que Ligirico (ERclu. $100=H E$ p. 2, 153) sea cognomen, no gentilidad.

${ }_{178} A E$ 1987, 610; (Castello) Eritalco: es dudoso si el adjetivo Addouie[n]sis, A. Mourinho, Brigantia 7, 1987, n. $29=A E 1987,587=H E p .3,466$ hace referencia a un habitante de un castellum o de un uicus.

179 A. Holgado, $A E F E 3,1980$, pp. 89-96, cf. HEp. 3, 95.

180 J. J. Sayas, ETF ser. 2, n. 1, 1988 (Hom. Ripoll), pp. 233-246; Id., J. L. Sánchez, Nuevas inscripciones cacereñas, Anejos Gerión 2, 1989 (Hom. Moreno Díaz), pp. 417-440: algunas con antropónimos indígenas, v. HEp. 3, 125-126; en esta misma provincia: J. L. Gamallo-H. Gimeno, CuPAUAM 17, 1990, pp. 277-306, con algunos antropónimos nuevos; en la provincia de Ávila: M." R. Hernado, Mem. H. ${ }^{a}$ Ant. . 10, 1989, pp. 197-218. Sobre la onomástica de los vascones: J. L. Ramírez, Act. $2{ }^{\circ}$ Congr. H. ${ }^{a}$ Gral de Navarra, Anejos PV 14, pp. 287-293.

181 J. A. Morena, El santuario ibérico de Torreparedones, Córdoba 1989, pp. 46-47 y 72 nt. 71, vid. A. M." Canto, HEp. 3, 160.

${ }^{182}$ Cf. supra, n. 8.

183 P. Sillières, «La raretè des voies Romaines en Hispania méridionale: explications et conséquences", Labor omnibus unum, in honorem G. Walser, Stuttgart 1989, pp. 105-111; Id., "Voies Romaines et limites de provinces et de cités en Lusitanie», Table Ronde "Villes de Lusitanie» (supra, n. 7), pp. 73-88.

184 J. M. Iglesias Gil-J. A. Muñiz, Las comunicaciones en la Cantabria romana, Santander 1992; A. R. de Miguel, Las comunicaciones en época romana en Alava, Navarra y 
sistema de financiación de la red viaria, en el que están implicados: el gobernador provincial, las legiones, los municipios, las comunidades y los ricos propietarios ${ }^{185}$.

Se duda de si un miliario incompleto aparecido en la provincia de Castellón corresponde a CIL II 4951, perdido ${ }^{186}$; otro, fechado en el a. 55, es el primero que se conoce en el tramo de la Vía de la Plata entre Salamanca y Astorga ${ }^{187}$; otro de Nerón se ha hallado en la Meseta Norte ${ }^{188}$; uno nuevo de Tiberio pertenece a la vía Emerita-Bracara ${ }^{189}$.

\section{Economía y comercio: marcas de ánforas; instrumenta uaria}

En una obra de conjunto, titulada Aceite de oliva y salazones de pescado: factores geoeconómicos de Bética y Tingitana, publicada por M. Ponsich ${ }^{190}$, se ofrece una lista detallada de los lugares costeros productores de garum y de conservas de pescado: un centenar de localidades entre el S. de España, el $\mathrm{N}$. de Marruecos y el Algarve; por otra parte, los lugares donde se fabrican las ánforas destinadas a envasar estos productos, concentrados en la región gaditana; se desarrolla este comercio a partir de Augusto, durante los siglos I

La Rioja; J. F. Clariana, «Les vies de comunicació del Maresme a l'Antiquitat: estat de la questió», Est. Mataró 5, 1988 (1989), pp. 7-32; J. Sánchez Real, «La Via Augusta y el puente de Francolí", BATarragona 10-11, 1988-89, pp. 135-167; F. Arasa, "Los miliarios de la Vía Augusta en el País Valenciano", Symp. Red Viaria (supra, n. 8), pp. 21-33; R. López Domech, «La red viaria romana en la región oretana», MCV 26, 1990, pp. 75-96; A. González Cordero, "Algunas notas sobre los miliarios de la Vía de la Plata en el tramo comprendido entre 'ad Sorores' y 'Castra Caecilia'), El miliario 27, 1990, pp. 17-19.

185 E. Melchor, "Sistemas de financiación y medios de construcción de la red viaria hispánica", Habis 23, 1992, 121-137.

186 Esta es la opinión de F. Arasa, BCEMA 24, 1988, pp. 18-19; contra, J. Corell, EJR Pamplona, 1989, pp. 15-18 = HEp. 2, 270; Id., J. Vicent, CPAC 12, 1986, pp. 251-252; J. Corell et alii, Fortunatae 4, 1992, pp. 208-210.

Otros de la región oriental de la Tarraconense: M. J. Massó, Symp. Red Viaria (supra, n. 8), pp. 347-354; J. Maya-M." José Pena, Est. Ant. 3, 1986, pp. 155-161: miliario de Augusto en Ilerda, fechado entre los años $15 / 5$ a. C., quizá el a. 8 a. C. como otros de la zona, en posible relación con el establecimiento de la Colonia Caesaragustana; J. y M. Bañales, Anejos PV 14, 1992 (1993), pp. 183-193: del a. 238 en Artajona (Navarra).

187 V. Aguado, I Congr. Inst. Astorga Romana (supra, n. 12), pp. 271-288 = $A E 1987$, 612, cf. HEp. 2, 734, T. Mañanes, Archivos Leoneses 89-90, 1991, p. 375 s. publica un «tambon» de arenisca fragmentario, también de Astorga; debe de ser un miliario de Augusto.

188 L. Sagredo et alii, HA 14, 1990, pp. 23-32; otros de la zona central: J. A. Abásolo, I Congr. H. ${ }^{a}$ Zamora, T. 2, Zamora 1990, pp. 539-544; M. J. Borobio-J. Gómez Pantoja-F. Morales, Celtiberia 74, 1987, pp. 241-243: uno de Licinio, a 312 (HEp. 2, 624), y otro de Decio, a 250 (HEp. 2, 660) en la provincia de Soria.

189 J. de Silva-P. J. Cardoso, $F E$ 42, 189; otros de la zona occidental: J. Candeias, FE 33, 152, de Constantino; S. Ferrer, Larouco 1, 1991, pp. 173-174, de Constancio II.

190 Madrid, 1988. Sobre un hallazgo que documenta la actividad importadora de salsas de pescado, vid. la nota de I. Rodríguez Temiño, AEArq. 63, 1990, pp. 292-295. 
y II. El mismo Ponsich continúa publicando los volúmenes sobre la zona bética productora de aceite ${ }^{191}$. El comercio es sin duda fuente de riqueza de personajes que alcanzan notoriedad a nivel local o provincial: uno de estos casos -el de Manilius Praesens, flamen de la Citerior c. 165/170 - ha sido estudiado por Haley ${ }^{192}$; otros intentos de conectar la producción de aceite con familias notables son los hechos por Remesal y F. Jacques ${ }^{193}$.

El propio Remesal ha hecho balance sobre el estudio de las ánforas a lo largo de un decenio ${ }^{194}$. El esfuerzo de los investigadores se centra en deslindar las distintas funciones que corresponden a las anotaciones de los tituli picti, cuestión en la que comenzamos a ver con cierta claridad; son importantes en este sentido las aportaciones de Rodríguez Almeida ${ }^{195}$. Chic presenta un catálogo de las ánforas béticas en tituli picti ${ }^{196}$; especial interés ofrece el estudio de Liou-Gassend sobre las inscripciones pintadas en ánforas halladas en $L$ 'épave Saint Gervais 3, datado a mediados del siglo II ${ }^{197}$. Otros estudiosos han elaborado catálogos locales de marcas anfóricas ${ }^{198}$. En una inscripción pintada sobre ánfora del tipo Dressel 1 se pueden reconstruir los cónsules del a. 90

191 M. Ponsich, Implantation rurale antique sur le Bas Guadalquivir, IV (Écija, Dos Hermanas, Los Palacios y Villafranca, Lebrija, Sanlúcar de Barrameda), Madrid 1991 (Col. de la Casa de Velázquez, n. 33). Los volúmenes anteriores se vienen publicando desde 1974 (II, 1979; III, 1987).

192 E. W. Haley, "Roman Elite Involvement in Commerce: the Case of the Sapnish TT. Mamilii», AEArq 61, 1988, pp. 141-156. Sugiere una revisión: los que Mayet cree officinatores quizá eran notables municipales.

193 Vid. supra, nt. 75. Interesante es también el trabajo de F. Mayet, «Les figlinae dans les marques d'amphores Dressel 20 de Bétique», REA 88, 1986 (1988), pp. 285-305.

194 J. Remesal, "Anfore romane e storia economica: un decenio di ricerche», Act. Colloq. de Siena, Roma 1989, pp. 489-503, cf. $A E$ 1989. 356 b). Véase también: Id., «El aceite bético durante el Bajo Imperio", Ant. y Crist. 8, 1991, pp. 355-362.

195 E. Rodríguez Almeida, Los 'tituli picti' de las ánforas olearias de la Bética I: 'Tituli picti' de los Severos y la 'ratio fisci'. Madrid 1989; Id., "Diffusores, Negotiatores, Mercatores, Olearii», bull. Comme. Arch. Communale di Roma 92, 1987-88, pp. 299-306: sobre los tituli $\beta$; Id., "Anforas olearias béticas: cuestiones varias», Alimenta (Hom. Ponsich), Anejos Gerión 3, Madrid 1991, pp. 243-260.

196 G. Chic, Epigrafia anfórica de la Bética II, Sevilla 1988, cf. $A E$ 1989, 356 a). Relacionado con estos estudios está: E. Pérez Fernández et alii, "El Portus Gaditanus estación aduanera de la Bética», Rev. de Arq. 104, 1989, pp. 29-38.

197 B. Liou-J. M. Gassend, Archaeonautica 10, 1991, 157-264.

198 A. Mantilla, "Marcas y ánforas encontradas en Saguntum», Saguntum 21, 1987-88, pp. 397-416; C. Aranegui, "Testimonios del vino saguntino", Hom. Recaséns, Tarragona 1992, pp. 35-43; R. Pascual i Guasch, Index d'estampilles sobre amfores catalanes, Barcelona 1992 (Cuad. de Arg. n. 5); J. Miró, «La producció d'amfores al Maresme: una sintesi», La villa Romana de Can Sanç 2, S. Andreu de Llavaneras 1989, pp. 5-13; E. Serrano Ramos et alii, «Notas sobre la producción de ánforas en la Huerta del Rincón (Torremolinos, Málaga)», Baetica 13, 1991, pp. 149-151; J. Remesal, «Die Stempel auf Amphoren des Typs Dressel 20 aus Worms», Arch. Korrespondenzblatt 19, 1989, pp. 351360 . 
a. C. ${ }^{199}$; E. Rodríguez Almeida he recogido algunos curiosos grafitos sobre las ánforas del Testaccio ${ }^{200}$. Estamos a la espera de los resultados de las excavaciones hechas por Blázquez, Remesal y Rodríguez Almeida en el Testaccio.

La arqueología submarina ha sacado a la luz un importante cargamento de lingotes de plomo del siglo I: es el más abundante de los hasta ahora conocidos de procedencia hispana; de los productores - una familia de Minucii- no es posible por ahora saber nada más ${ }^{201}$; otro equipo ha elaborado una lista de sellos en lingotes de plomo procedentes de las minas de Sierra Morena ${ }^{202}$. Un hallazgo en Ampurias ha dado a conocer un fragmento de carta comercial escrita en dialecto jonio sobre placa de plomo ${ }^{203}$.

Son muy abundantes los estudios sobre marcas de sigillata: pueden agruparse en dos grandes bloques: a) los que reúnen el material según el lugar del hallazgo o conservación ${ }^{204}$; b) los que persiguen la trayectoria de una marca

199 J. Miró, Documents d'Archéologie Meridionale 9, 1986, pp. 201-295 = Id., Faventia 10,1988 , pp. 113-116. Otros hallazgos aislados: S. Martin Kilcher-U. Schillinger Häfele, Mainz 2, 84-85, 1989-90, pp. 273-278: ánfora bética para salsa de pescado, con titulus pictus hallado en Mainz; M. Orfila-J. Merino, Saguntum 22, 1989, pp. 465-470: ánfora de Tubusuctu (Mauritania Cesariense) en Mallorca; S. Martin Kilcher, AEArq. 62, 1989, pp. 241-243: ánfora Dressel 20 hallada en Angst, datable en a. 80/90.

200 Bull. della Comm. Arch. Communale di Roma 93, 1989-90, pp. 35-40.

201 B. Liou-C. Domergue, «Le commerce de la Bétique au 1. ${ }^{\text {er }}$ Siècle de notre ère L'épave Sud-Lavezzi 2" Achaeonautica 10, 1991, pp. 11-124. El estudio contiene también la interpretación de 114 marcas sobre lingotes de cobre.

${ }^{202}$ D. Colls-C. Domergue-V. Guerrero, Archaeonautica 6, 1986, pp. 31-80, cf. $A E 1988$, 832: material fechado a fines del siglo I o comienzos del II. Otras marcas sobre plomo en la provincia de Huelva, v. CILA I, n. $20=H E p .3,212$; n. $52=H E p .3,208$.

${ }^{203}$ E. Sanmartí-R. A. Santiago, ZPE 77, 1989, pp. 36-38; R. A. Santiago, ZPE 80, 1990, pp. 79-80; Id., ZPE 82, 1990, p. 176; Id., ZPE 84, 1990, p. 14.

${ }^{204}$ J. H. Fernández et alii, Marcas del T. S. del Museo Arqueológico de Ibiza, Ibiza 1992; F. Tarrats, "T. S. del passatge de Cobos (Tarragona)", Hom. Recaséns. Tarragona 1992, pp. 155-176; A. Pérez Almoguera, La T. S. del antic Portal de Magdalena, Lleida 1990; M. Vera, "Marcas o sellos y grafitos en fondo de vasos de T. S.», Arse 23, 1988, pp. 45-56; A. Ribera, "Marcas de T. S. del Tossal de Manises (Alicante)», Lucentum 7-8, 1988-89, pp. 171-204; C. Pérez et alii, «Marcas de T. S. del Tossal de Manises (Alicante)», Lucentum 7-8, 1988-89, pp. 171-204; C. Pérez et alii, «Marcas de alfareros sobre T. S. en Cantabria», Altamira 48, 1989, pp. 7-23; M. E. Solovera-T. Garabito, "Los talleres de Tritium Magallum. Nuevas aportaciones», $H A$ 14, 1990, pp. 69-89; V. G." Marcos, «Marcas de alfarero en sigillata hispánica halladas en León», Tierras de León 77-78, 1990, pp. 89114; F. Sáenz de Urturi, «Marcas de alfareros y epígrafes sobre T. S. de yacimientos alaveses", EAA 16, 1988, pp. 557-576; S. Andrés-J. A. Tirado, Berceo 120, 1991, pp. $17-$ 19: 14 marcas encontradas en Varea (Logroño); M. P. Sáenz, «Marcas de alfarero y grafitos en T. S. de Varea», Mus. Zaragoza 7, 1988, pp. 37-56; E. Serrano et alii, Baetica 10, 1987, pp. 219-225: en la prov. de Málaga; A. Burgueois-F. Mayet, Les sigillées. Fouilles de Belo VI, Madrid 1991; B. Pérez Outeriño, Cuadernos Emeritenses 3, Madrid 1990: sellos de sigillata itálica encontrados en Mérida. 
concreta $^{205}$. Menos frecuente es la agrupación según el tipo de objetos ${ }^{206}$. Otro apartado es el correspondiente a los grafitti en este material ${ }^{207}$. Otros sellos se encuentran sobre objetos metálicos varios ${ }^{208}$.

\section{Inscripciones cristianas y de época visigoda}

En este apartado, la gran aportación es la edición de pizarras visigodas por I. Velázquez ${ }^{209}$, en la que se contienen 104 pizarras: algo más de la mitad proceden de la provincia de Ávila y 38 de la de Salamanca ${ }^{210}$. La autora ofrece una nueva lectura de la pizarra de Carrío, publicada por Gómez Moreno y revisada después por Canellas y por J. Gil: la pieza es un conjuro contra el granizo, con una mezcla de creencias populares y cristianismo, y se fecha hacia el a. 750; un signum Salomonis encabeza y cierra el texto ${ }^{211}$. La misma autora ha estudiado los epígrafes latinos de la Cueva de la Camareta: más de treinta grafitti, textos breves y formularios, en su casi totalidad cristianos ${ }^{212}$. J. L.

${ }^{205}$ E. Manfra-M. L. Palanques, "La marca $C$. Oppi a través de la Ruta de la Plata», Simp. Red Viaria (supra n. 8), pp. 317-323, T. Garabito et alii, «El alfarero Segius Tritiensis», Hom. Montero, Anejos Gerión 2, 1989, pp. 441-459; R. A. Luezas, Una estampilla de dolium de Varea (Logroño), Caesaragusta 66-67, 1989-90, pp. 159-165; Porci Segensis Birri (entiendo que será Porcius Birrus, de origen Segensis); J. A. Minguez, Act. Congr. de Lézoux, Marseille 1989, pp. 181-189: marcas de G. Valerius Verdullus y su difusión por el valle del Ebro; E. Gil, Act. $2{ }^{\circ}$ Congr. H. ${ }^{a}$ Gral. de Navarra, Anejos PV 14, pp. 217-228: producción de $G$. Valerius Verdullus en Viana; M. Roca, "Sobre la presencia de ciertas marcas en T. S. itálica en Pollentia y Tarragona», Hom. Recaséns. Tarragona 1992, pp. 105113 (empiezan a llegar a mediados del siglo I a. C.); J. Agraz, AEArq. 62, 1989, pp. 244245: sello (Sabinu)s Fe(cit) en Tarragona.

206 C. Pérez-C. Fernández Ibáñez, «Sellos de alfarero sobre mortaria en la Península Ibérica", Publ. Inst. Téllez 60, 1989, pp. 67-98; C. W. Haley, "The Lamp Manufacturer Gaius Iunius Draco, Münst. Beitr. 12, 1990, pp. 1-13; FE 37, n. 168: tegulae en Lusitania (Ossonaba, conu. Pacensis): L. S. P.

207 J. Corell, Arse 24, 1989, pp. 29-33; J. Sánchez Lafuente, HA 15, 1991, pp. 207-238; J. Murillo-M. L. de Sus, El Solar de la Diputación Provincial de Huesca, 1987, pp. 56-57; M. Mayer-I. Roda, Fonaments 7, 1988, pp. 238-239; J. M. Abascal, AEArq. 63, 1990, p. 275; S. Andrés-J. A. Tirado, Berceo 120, 1991, pp. 20-21; J. d’Encarnação, Sto. Tirso Arqueologico 2, 1992, pp. 7-14.

${ }^{208}$ F. Fernández, Alimenta (Hom. Ponsich) Madrid 1991, pp. 309-314: conjunto de matrices en bronce procedente de Sevilla; otros sellos de bronce, en CILA II, 1, nn. 219, 232, 260, 261, 262, otros dos sellos de bronce, procedentes de Palma del Río (Córdoba), edita A. U. Stylow, Ariadna 5, 1988, nn. 9 y 17; C. Aranegui, $A P L$ 19, 1989, pp. 263-264= HEp. 3. 395: sobre el brazo de una balanza: a) Imp. Cae Nerua Traiano Aug.; b) Ger. Dac. cos. VI, exa(cta) in Capitolio, corresponde al a. 112; C. Blánquez, HA 13, 1986-1989, pp. 229-237: T. C. M. en anillo de oro, fechado en s. III/IV, cf. HEp. 3, 244.

${ }^{209}$ I. Velázquez, Las pizarras visigodas. Ed. critica y estudio, Murcia 1989.

210 Vid. HEp. 3, 30-87 y 281-318.

211 Piz. V. n. $104=$ HEp. 3, 24.

212 Ant. y Crist. 5, 1990, pp. 315-319. 
Ramírez publica un epitafio de la provincia de Badajoz que presenta fórmulas no recogidas por Vives ${ }^{213}$. A. Azkárate, en un estudio sobre arqueología cristiana en el País Vasco, recoge diecisiete grafitti $^{214}$. Son varios los hallazgos de epígrafes cristianos sobre diversos objetos ${ }^{215}$ y varias también las relecturas de epígrafes ya conocidos ${ }^{216}$.

\section{Varia}

Ya hemos aludido más arriba ${ }^{217}$ a diversos catálogos en los que se reúnen inscripciones musivas; quizá la más interesante inscripción sobre mosaico de los hallazgos en los últimos años es la de Trahius, encontrada en Italica ${ }^{218}$; otros varios con inscripción se han encontrado en la villa de Carranque ${ }^{219}$; de Puente Genil (Córdoba) procede otro nuevo con diálogos de carácter cómico ${ }^{220}$; uno del siglo Iv, hallado en Mérida, contiene siete inscripciones griegas relativas a los siete sabios ${ }^{221}$; en la antigua Celsa (prov. Zaragoza) se ha encontrado uno con la leyenda Caue canem ${ }^{222}$.

213 J. L. Ramírez Sádaba, Ant. y Crist. 8, 1991, pp. 89-98, datable entre fin s. III y comienzos del s. v. Otras inscripciones nuevas: J. Freire, B. Aur. 18-19, 1988-89, pp. 133142; A. U. Stylow, Ariadna 5, 1988, n. $10=H E p .2$, 353; A. Ibánez Castro, $A A A$ 3, 1985, pp. 125-126, cf. HEp. 2, 318, 319, 321; E. Hernández, Ant. y Crist. 7, 1990, p. 588 (foto, sin lectura); CILA II 1, n. 146; FE 26, n. 121; 38, nn. 171-173; 40, n. 180; 41, nn. 181-183; 42, n. 187. En griego: $F E 41$, nn. 184-186; I. Roda, Fonaments 7, 1988, pp. 231-233= $H E p$. 2, 24; I Millán-A. Blanco, BRAH 186, 1989, pp. 209-219 dan noticia de un hallazgo, en el mausoleo del apóstol Santiago, de un título sepulcral griego que interpetan como el de su discípulo San Atanasio; cf. el comentario escéptico de Stylow en HEp. 3, 173.

214 A. Azkárate, Arqueologia cristiana de la antigüedad tardia en Álava, Guipúzcoa y Vizcaya, Vitoria Gasteiz 1988, cf. HEp. 2, 3-5, 186, 187. Otro grafito, en una iglesia visigoda de la provincia de Cáceres: L. Caballero-I. Velázquez, AEArq. 62, 1989, pp. 262-271.

215 En anillo de oro: J. M." Sánchez, Habis 21, 1990, pp. 229-233, fechable en el s. VI; I. Velázquez, Arte y poblamiento en el $S E$ peninsular durante los últimos siglos de civilización romana, Murcia 1988, pp. 255-258. Plomo con doble inscripción: I. Velázquez, Gerión 7, 1989, pp. 269-275 = HEp. 3, 25.

${ }^{216}$ I. Velázquez, HEp. 3, 278: revisión de B. Aur. 18-19, 1988-1989, pp. 133-141; Id., ibid., n. 102, sobre Fonaments 6, 1985, pp. 193-211; J. Corell, Saitabi 39, s1989, pp. 63-72, relectura de ICERV 279: no aparece en ella el nombre de Justiniano sino el del obispo Anesio, se fecha en a. 648; J. Mangas, HEp. 2, 25, observaciones críticas a MHA 8, 1987, pp. 182-186; Id., ibid., n. 26: es muy dudosa la interpretación cristiana; M. Mayer, Fonaments 7, 1988, p. 218, HEp. 2, 272, nueva lectura de CPAC 12, 1986, pp. 261-266.

${ }^{217}$ Supra, n. 28.

218 V. supra, n. $151 \mathrm{a}$.

219 D. Fdez. Galiano, Mosaicos romanos, Actas I mesa redonda hispana francesa sobre mosaicos romanos, Madrid, 1989, pp. 259-260, cf. HEp. 3, 374-376.

220 A. Daviault-J. Lancha-L.A. López Palamo, Madrid Publ. C. V., Et et doc. III, 1987, cf. $A E$ 1987. $501=H E p .3,170$.

${ }_{221}$ J. M. Álvarez Martínez, Anas 1, 1988, pp. 99-120, cf. HEp. 2, 41.

222 J. A. Lasheras, Mosaicos romanos, v. supra, n. 219, p. 97, cf. HEp. 3, 417. Nuevas lecturas de mosaicos ya conocidos: J. Gómez Pallarés, M. Mayer, sobre Balil, PV 26, 1965 , 
La edición de cuatro hermas-retrato, procedentes de Emérita, completa la serie anteriormente publicada por Stylow con otros colaboradores; la n.3 -inédita - dice: C. Sentio / Macro / Ponticus clie $(n s){ }^{223}$. Rodríguez Colmenero publica una inscripción rupestre, de lectura poco segura ${ }^{224}$. Sobre la reutilización de soportes en el conuentus Tarraconensis ha escrito M. Mayer ${ }^{225}$.

Varios hallazgos, en diferentes lugares, están relacionados con los juegos gladiatorios ${ }^{226}$.

Algunos estudiosos han llamado la atención sobre hispanos fuera de Hispania o sobre la inmigración a Hispania desde otras provincias ${ }^{227}$.

También se ofrecen algunas novedades en el ámbito de los epitafios métri$\cos 228$.

Son dignos de mención, por último, algunos epígrafes funerarios en los que se detallan las circunstancias de la muerte 229 .

\section{Carmen Castillo}

pp. 284-285, v. HEp. 3, 235; sobre M. Donderer, «Die Mosaisisten der Antike und ihre wirtschaftiliche und soziale Stellung», Erlanger Forschungen Reihe A. Geisteswiss 48, 1989, nn. 101-102, v. A. Canto, HEp. 3, 351.

223 A. U. Stylow, Anas 2-3, 1989-90, pp. 195-205.

224 A. R. Colmenero-S. Ferrer, Aquae Flauiae n.s. 1, 1988, cf. HEp. 3, 491.

225 M. Mayer, Hom. Recaséns, Tarragona, 1992, pp. 75-82.

226 Belo V n. $10=$ Hep. 2. 232: un fragmento de bronce, en lin. 2: [gladi?]atorio; $\mathrm{M}$. Mayer-I. Roda, Fonaments 7,1988 , p. $243=H E$ p. 2, 60: tesera lusoria fechable en el s. a. C.; Andrés-J. A. Tirado, Berceo 120, 1991, pp. 7-64: contiene inscripción fragmentariạ en bajo relieve de vidrio con tres figuras de gladiadores; J. L. de la Barrera, Anas 1, 1989, pp. 121-124: funeraria de un secutor frigio enterrado en Mérida, en la segunda mitad del s. II, cf. HEp. 2, 39: es la primera mención de secutor en la epigrafia hispana. Quizá corresponde también a un gladiador el epígrafe de Córdoba recogido en $H E p .2,351$.

227 H. Solin, «Un tuccitano a Casino», Religio deorum (supra, n. 9), pp. 445-448. B. Nieto - A. Ventura, La ciudad romana de Acinipo, Ronda 1990, pp. 149-158: nuevo epigrafe referente a un ciudadano del África Proconsular. Algo anterior al período que nos ocupa es la obra de E. W. Haley, Foreigners in Roman Spain, Ann Arbor 1986.

228 J. Corell, «El epitafio poético de L. Iulius Aptus (Mértola, Portugal)», Conimbriga 27, 1988, pp. 141-151: Id., "El epitafio poético del niño M. Marius Lasciuus (Montán, Castellón)", Act. VII C.E.E.Cl., Madrid 1989, pp. 73-78: sobre CLE $2183=$ Mariner p. 175: no tiene esquema métrico; es una composición commatica. M. Jiménez Cobo, Nuevos escritos sobre Mancha Real, Jaén 1988, p. 35: restos de un carmen sepulcral cuya lectura da A. U. Stylow, $H E p$. 3, 240.

${ }^{229} \mathrm{~J}$. Corell, Bol. de la sociedad castellonense de Cultura, 68, 3, (s. a.): [in flum]en pro[apsus es] t et decessit; como apoyo de la reconstrucción de Corell, podría aducirse Nep. Ages. 8, 6: in morbum implicitus decessit; Faventia 9, 2, 1987, pp. 107-118, p. 208: dolo latronum manu occisus sum; otro individuo a latronibus occisus conocemos en Navarra (CIL II 2968, Oteiza). 